\title{
Noise Benefits of Rotor Trailing Edge Blowing for a Model Turbofan
}

Richard P. Woodward, E. Brian Fite, and Gary G. Podboy Glenn Research Center, Cleveland, Ohio 


\section{NASA STI Program . . . in Profile}

Since its founding, NASA has been dedicated to the advancement of aeronautics and space science. The NASA Scientific and Technical Information (STI) program plays a key part in helping NASA maintain this important role.

The NASA STI Program operates under the auspices of the Agency Chief Information Officer. It collects, organizes, provides for archiving, and disseminates NASA's STI. The NASA STI program provides access to the NASA Aeronautics and Space Database and its public interface, the NASA Technical Reports Server, thus providing one of the largest collections of aeronautical and space science STI in the world. Results are published in both non-NASA channels and by NASA in the NASA STI Report Series, which includes the following report types:

- TECHNICAL PUBLICATION. Reports of completed research or a major significant phase of research that present the results of NASA programs and include extensive data or theoretical analysis. Includes compilations of significant scientific and technical data and information deemed to be of continuing reference value. NASA counterpart of peer-reviewed formal professional papers but has less stringent limitations on manuscript length and extent of graphic presentations.

- TECHNICAL MEMORANDUM. Scientific and technical findings that are preliminary or of specialized interest, e.g., quick release reports, working papers, and bibliographies that contain minimal annotation. Does not contain extensive analysis.

- CONTRACTOR REPORT. Scientific and technical findings by NASA-sponsored contractors and grantees.
- CONFERENCE PUBLICATION. Collected papers from scientific and technical conferences, symposia, seminars, or other meetings sponsored or cosponsored by NASA.

- SPECIAL PUBLICATION. Scientific, technical, or historical information from NASA programs, projects, and missions, often concerned with subjects having substantial public interest.

- TECHNICAL TRANSLATION. Englishlanguage translations of foreign scientific and technical material pertinent to NASA's mission.

Specialized services also include creating custom thesauri, building customized databases, organizing and publishing research results.

For more information about the NASA STI program, see the following:

- Access the NASA STI program home page at http://www.sti.nasa.gov

- E-mail your question via the Internet to help@sti.nasa.gov

- Fax your question to the NASA STI Help Desk at 301-621-0134

- Telephone the NASA STI Help Desk at 301-621-0390

- Write to: NASA Center for AeroSpace Information (CASI) 7115 Standard Drive Hanover, MD 21076-1320 


\section{Noise Benefits of Rotor Trailing Edge Blowing for a Model Turbofan}

Richard P. Woodward, E. Brian Fite, and Gary G. Podboy

Glenn Research Center, Cleveland, Ohio

Prepared for the

45th Aerospace Sciences Meeting and Exhibit

sponsored by the American Institute of Aeronautics and Astronautics

Reno, Nevada, January 8-11, 2007

National Aeronautics and

Space Administration

Glenn Research Center

Cleveland, Ohio 44135 
This work was sponsored by the Fundamental Aeronautics Program at the NASA Glenn Research Center.

Level of Review: This material has been technically reviewed by technical management.

Available from

NASA Center for Aerospace Information

7115 Standard Drive

Hanover, MD 21076-1320
National Technical Information Service 5285 Port Royal Road Springfield, VA 22161

Available electronically at http://gltrs.grc.nasa.gov 


\title{
Noise Benefits of Rotor Trailing Edge Blowing for a Model Turbofan
}

\author{
Richard P. Woodward, E. Brian Fite, and Gary G. Podboy \\ National Aeronautics and Space Administration \\ Glenn Research Center \\ Cleveland, Ohio 44135
}

\begin{abstract}
An advanced model turbofan was tested in the NASA Glenn 9- by 15-Foot Low Speed Wind Tunnel (9x15 LSWT) to explore far field acoustic effects associated with rotor Trailing-Edge-Blowing (TEB) for a modern, 1.294 stage pressure ratio turbofan model. The TEB rotor (Fan9) was designed to be aerodynamically similar to the previously tested Fan1, and used the same stator and nacelle hardware. Fan9 was designed with trailing edge blowing slots using an external air supply directed through the rotor hub. The TEB flow was heated to approximate the average fan exit temperature at each fan test speed. Rotor root blockage inserts were used to block TEB to all but the outer 40 and $20 \%$ span in addition to full-span blowing. A configuration with full-span TEB on alternate rotor blades was also tested. Far field acoustic data were taken at takeoff/approach conditions at 0.10 tunnel Mach. Farfield acoustic results showed that full-span blowing near $2.0 \%$ of the total flow could reduce the overall sound power level by about $2 \mathrm{~dB}$. This noise reduction was observed in both the rotor-stator interaction tones and for the spectral broadband noise levels. Blowing only the outer span region was not very effective for lowering noise, and actually increased the far field noise level in some instances. Full-span blowing of alternate blades at $1.0 \%$ of the overall flow rate (equivalent to full-span blowing of all blades at $2.0 \%$ flow) showed a more modest noise decrease relative to full-span blowing of all blades. Detailed hot film measurements of the TEB rotor wake at $2.0 \%$ flow showed that TEB was not every effective for filling in the wake defect at approach fan speed toward the tip region, but did result in overfilling the wake toward the hub. Downstream turbulence measurements supported this finding, and support the observed reduction in spectral broadband noise.
\end{abstract}

\section{Introduction}

An advanced model turbofan was tested in the NASA Glenn 9x15 LSWT to explore far field acoustic effects associated with rotor TEB. Previous research has shown that the rotor viscous wake may be significantly reduced by injecting "make up" air at or near the trailing edge. Reduction of the rotor wake results in less wake interaction with the downstream stator and therefore less rotor-stator interaction noise. This noise reduction is particularly beneficial for the interaction tone levels at multiples of Blade Passing Frequency (nBPF), but may also be seen in the broadband noise levels. This paper presents far field acoustic results for a modern high bypass ratio, low tip speed model turbofan with rotor trailing edge blowing. These model tests were conducted in an anechoic low-speed wind tunnel at the NASA Glenn Research Center in 2005.

The concept of reducing blade wake through trailing edge blowing has been investigated in the literature. Reference 1 shows water tunnel results for a blade with trailing edge jets. This reference showed that the blade wake defect could be significantly reduced by proper injection of makeup fluid at the blade trailing edge, and suggests that this technique might have benefits for turbofan engines. Brookfield and Waitz (ref. 2) tested a modern 22-in. diameter model turbofan with rotor TEB in a transient blow-down facility. Their results showed that the first three BPF harmonics amplitudes could be reduced by as much as $85 \%$ (measured in-duct 1.5 chords downstream of the rotor) using a blowing mass flow less than $2 \%$ of the stage throughflow. Although encouraging, these results were compromised by facility limitations, including non-anechoic accommodations for far field noise measurements.

Virginia Tech (ref. 3) explored acoustic benefits of inlet strut trailing edge blowing for a small turbofan simulator in an anechoic chamber. These tests were intended to screen possible noise reduction technologies applicable to a transonic turbofan engine such as would be required for a High Speed Civil Transport. Reference 3 showed that the far field sound power level BPF could be reduced by as much as $4.4 \mathrm{~dB}$ by inlet strut blowing. Of course, there remained a component of the BPF due to rotor-stator interaction.

Very encouraging fan noise reduction results with TEB have been documented for the Active Noise Control Fan (ANCF (refs. 4 to 5)) tested in the NASA Glenn Aero-Acoustic Propulsion Laboratory (AAPL). The ANCF is a very low speed, low pressure ratio 48-in. diameter turbofan simulator. The ANCF is extensively instrumented for aeroacoustic in-duct measurements, including a rotating rake for acoustic mode identification and measurement. 
High quality far field acoustic measurements can be acquired in the anechoic AAPL. TEB tests for the ANCF (refs. 6 to 9) showed far-field PWL tone reductions for the first three rotor-stator interaction tone orders of 5.4, 10.6, and $12.4 \mathrm{~dB}$. However, there still remained the question as to the effectiveness of TEB for a more representative modern turbofan.

This paper presents far field acoustic results for a 1.284 stage pressure ratio, $840 \mathrm{ft} / \mathrm{s}$ tip speed model turbofan with rotor trailing edge blowing. These tests were conducted in the NASA Glenn 9x15 LSWT (refs. 10 to 12) at 0.10 Mach, which is representative of takeoff/approach conditions and sufficient to achieve acoustic flight effect (ref. 13).

\section{Description of Test Apparatus}

\section{A. Fan stage}

The TEB fan stage used most of the hardware from the previously tested Advanced Ducted Propulsor (ADP) Fan1 (ref. 14). The 22-in. diameter fan had 18 rotor blades and 45 stator vanes with a passive core (table 1). This rotor/stator ratio satisfies the Tyler-Soffrin criterion for cut-off of the fundamental rotor-stator interaction tone (ref. 15). Aerodynamic results for this TEB fan stage are presented in reference 16.

The ADP Fan1 blade geometry was used as the basis for the blown rotor designated "Fan9." Computational fluid dynamic techniques were used to define the blade internal flow structure to optimize the trailing edge blowing pattern. Inserts could be placed in the Fan9 blade spars to block some of the blowing passages for "partial blowing" tests. Acoustic data were acquired using these inserts with only the outer 20 and $40 \%$ of the span blown in addition to full-span blowing. Both the trailing edge blowing flow rate (as a percent of total fan flow) and blowing temperature could be adjusted. Data were initially taken with "cold" $70{ }^{\circ} \mathrm{F}$ blowing and with the blowing air temperature adjusted to the approximate average fan exit temperature ("hot") at each fan test speed to minimize possible temperature-induced flow distortions. Subsequent data were only taken with "hot" blowing since blowing effectiveness was marginally better with the heated flow. A slightly oversized exit nozzle was used with the Fan9 TEB because of the additional exit airflow. The original "flight" nozzle was used with the unblown reference Fan 1. Table 2 shows the matrix of acoustic data taken for these TEB tests. figure 1 is a sketch of the Fan9 blowing geometry, and figure 2 is a 3D sketch of the test fan as mounted on the $5000 \mathrm{hp}$ drive turbine and pylon. The TEB air supply was ducted on the side of the support pylon and model support sting. The far-field acoustic microphone array was located on the opposite side of the model.

The hot film data was acquired using the bellmouth inlet and flight nozzle but with a different fan case to accommodate provisions for actuator mounting at several model stations. Additionally, the model allowed the rotorto-stator guide vane spacing to be varied. During the aerodynamic and acoustic performance tests the stator vanes were located 1.8 axial fan chords downstream of the rotor; during hot-film testing the stators were further downstream at a location 2.6 axial fan chords downstream of the rotor.

\section{B. Anechoic Wind Tunnel and Acoustic Instrumentation}

The NASA Glenn 9x15 LSWT is located in the low speed return leg of the 8x6 Supersonic Wind Tunnel. The tunnel test section walls, floor, and ceiling have acoustic treatment to produce an anechoic test environment. figure 3 is a sketch of the research fan installed in the 9x15 LSWT. Sideline acoustic data were acquired with a computercontrolled translating microphone probe and with three aft microphone assemblies mounted to the tunnel floor. The translating microphone probe acquired data at 48 sideline geometric angles from $27.2^{\circ}$ to $134.6^{\circ}$ relative to the fan forward axis of rotation centered on the rotor plane of rotation. The translating probe traverse was $89 \mathrm{in}$. from the fan rotational axis (about four fan diameters). A wall-mounted microphone probe was placed at a reference location adjacent to the translating probe home position $\left(134.6^{\circ}\right.$, maximum aft travel). The three fixed microphone assemblies were mounted at the home axial position to acquire aft acoustic data at geometric angles of $140^{\circ}, 150^{\circ}$, and $160^{\circ}$. Data were also acquired with an acoustic barrier wall installed adjacent to the fan which effectively blocked aft-radiated fan noise (fig. 4). The acoustic data were acquired through a digital computer system and stored for post-run analysis.

Figure 5 is a photograph of the research fan installed in the 9x15 LSWT (barrier wall not present). Downstream fixed microphones were not used with the wall installed because of acoustic blockage. The sideline traversing microphone probe may be seen to the left of the fan in this photograph.

Hot film flow surveys were taken downstream of the fan to further quantify rotor wake filling associated with the trailing edge blowing. Figure 6 is a sketch showing the location of these hot film surveys. Surveys were taken for the 
reference Fan 1 rotor (no blowing) and for Fan9 with 2.0\% full-span blowing and also for Fan9 with 1.07\% blowing on the outer $40 \%$ span. The downstream survey location (sta. 176.58) corresponds to the axial location of the stator leading edge in the TEB configuration. The stator was relocated further downstream for the hot film surveys to provide probe clearance.

\section{Results and Discussion}

\section{A. Fan Stage Aerodynamic Performance}

Fan9, with provisions for rotor trailing edge blowing, utilized the same flow path hardware as was used for the reference ADP Fan1. A slightly oversized exhaust nozzle (flight $+1.45 \%$ area) was used for the Fan9 blowing configurations because of the additional stage airflow associated with TEB. The fan map in figure 7 shows that the reference Fan1 (no blowing, flight nozzle) had essentially the same performance as Fan9 with $2.0 \%$ blowing (flight $+1.45 \%$ area nozzle).

The overall thrust for the model was required to make acoustic comparisons on an equal thrust basis. The thrust contribution for the fan was measured directly using a 2-component rotating force balance, measuring rotor thrust and torque. The nacelle thrust was also directly measured for Fan1 using a 6-component static balance. Therefore, for Fan1, the total thrust was the sum of the rotor and nacelle thrust corrected to standard day conditions. For Fan9, the rotor thrust was again measured directly; however, the nacelle balance was eliminated in the Fan 9 configuration to provide space for supplying the blowing air. For all Fan9 cases, the nacelle thrust was estimated using a curve fit of thrust as a function of total mass flow. The curve fit was generated using Fan1 data acquired using a static balance to directly measure thrust from a previous test. The total was then the sum of the measured rotor thrust added to the estimated nacelle thrust, again corrected to standard day conditions.

\section{B. Far Field Acoustic Performance}

\section{Full-span blowing}

Fan9 trailing edge blowing was most effective with full-span blowing using a TEB flow rate of $2.0 \%$ of the stage throughflow. Far field noise reductions were seen for this configuration for both rotor-stator interaction tones as well as some broadband noise levels. Figure 8 shows how the overall sound power level (integrated from $1 \mathrm{kHz}$ to 50 $\mathrm{kHz}$ ) changed with TEB blowing rate. The results of figure 8 are for Fan9 full-span blowing with the flight $+1.45 \%$ area exhaust nozzle and no acoustic barrier wall present. Clearly the most noise reduction occurred near a $2.0 \%$ blowing rate. Figure 9 shows the overall sound power level (OAPWL, calculated from 1 to $50 \mathrm{kHz}$ ) for reference Fan1 and for the various TEB blowing rates. Again, TEB blowing rates of 2.0 and $2.5 \%$ produced the lowest noise levels.

Trailing edge blowing was initially identified as a mechanism to reduce rotor-stator interaction tone levels by filling in the rotor wake and thereby reducing the magnitude of the stator fluctuating lift due to that wake. Figure 10 shows the noise benefits of $2.0 \%$ TEB for the $2 \mathrm{BPF}$ through $4 \mathrm{BPF}$ interaction tone orders. (The fundamental interaction tone (BPF) was essentially not present for this fan stage due to the cut-off design.) The sound power level (PWL) results of figure 10 were taken from $59 \mathrm{~Hz}$ bandwidth OAPWL spectra which were integrated over the entire sideline noise survey. TEB tone reductions were seen for the 2BPF tone somewhat above approach fan speed, with a maximum noise reduction of $6 \mathrm{~dB}$ at a corrected stage thrust of $730 \mathrm{lbf}$. (6700 RPMc), and continued at a somewhat reduced magnitude through the higher fan speeds. TEB tone reductions for the $3 \mathrm{BPF}$ tone were highest at approach fan speed $(5 \mathrm{~dB})$ and diminished to negligible benefits at cutback and higher fan speeds. TEB tone reductions for the $4 \mathrm{BPF}$ tone were negligible.

TEB was also seen to reduce broadband noise levels at frequencies below $7 \mathrm{kHz}$. PWL spectra for three fan speeds are shown in figure 11 for the reference Fan 1 and Fan 9 with $2.0 \%$ full-span blowing. Again, these spectra are integrated over the entire sideline noise survey. Broadband noise is thought to relate to downstream rotor wake turbulence, so these results suggest that TEB may reduce rotor wake turbulence as well as the wake defect. Broadband noise reductions were as much as $3 \mathrm{~dB}$ at approach fan speed, with lesser, but still significant reductions at higher fan speed.

The reference Fan1 spectra at cutback fan speed (7525 RPMc) was dominated by strong tones at multiples of about $1 \mathrm{kHz}$. The source of these tones, which were only seen in the Fan1 spectra (including repeat rebuilds and testing of Fan1) remains unknown. However, the $59 \mathrm{~Hz}$ spectral bandwidth made it possible to extract rotor-stator 
tone levels for Fan1 at cutback speed. This difficulty with the Fan1 spectra was only observed close to the cutback fan speed.

Sideline noise measurements were made at 51 locations corresponding to emission angles for $0.10 \mathrm{M}$ tunnel flow (relative to the rotor stacking line) from $25^{\circ}$ through $160^{\circ}$. These noise measurements were corrected for microphone, etc. response, for atmospheric attenuation, and adjusted to a 1 foot radius centered on the fan rotational axis. These "lossless" noise directivities for the reference Fan1 and Fan9 with 2.0\% TEB are presented in Figs. 12 through 16. Figure 12 shows directivities for the overall sound pressure level (OASPL) integrated from 1 to $20 \mathrm{kHz}$. Results are shown for the same three fan speeds used in figure 11. The OASPL is reduced by about $2 \mathrm{~dB}$ with $2.0 \%$ TEB at approach fan speed, with somewhat less noise reduction with increasing fan speed. These OASPL reductions are comparable in magnitude to what was observed for the overall sound power level (Figs. 8 and 9).

Tone and broadband sound pressure level (SPL) directivities were taken from the $59 \mathrm{~Hz}$ SPL spectra. These noise levels are approximate since they are plotted using the spectral frequency "bin" containing the tone of interest. Some additional tone energy was occasionally contained in adjacent frequency bins. Figures 13 through 16 show SPL directivities for the 2BPF through 4BPF rotor-stator interaction tones as well as representative directivities for a broadband spectral region between the 2BPF and 3BPF tones. SPL directivities at approach fan speed are shown in figure 13. TEB was most effective for the 3BPF and 4BPF tone and representative broadband level at this fan speed.

TEB becomes more effective at 6700 RPMc (fig. 14) for the 2BPF and 3BPF tone, with some benefit seen for the broadband noise level. TEB is somewhat effect for all three tone orders and the broadband level at cutback fan speed (fig. 15). At takeoff fan speed (fig. 16) TEB noise reduction is primarily seen for the 2BPF tone.

Far-field acoustic data with TEB were also taken with the acoustic barrier wall in place, effectively blocking noise radiating from the fan stage exhaust. However acoustic data were only taken for the reference Fan 1 and for Fan9 with $2.0 \%$ full-span blowing. Figure 17 shows the OAPWL as a function of fan speed for these two configurations with the barrier wall in place. TEB is seen to typically reduce the OAPWL by up to $2.5 \mathrm{~dB}$, with the greatest benefit at lower fan speeds. This noise reduction with TEB is comparable to what was observed without the barrier wall present (fig. 9). The noise signature of modern high bypass turbofans (Fan1 \& Fan9) tend to become aftdominated toward higher fan speeds, as evidenced in the noise drop-off at higher fan speeds for forward-radiated noise as seen in figure 17 .

\section{Partial-span blowing}

Rotor trailing edge blowing airflow must be taken from basic engine airflow, and in so doing there is some loss in overall stage efficiency. If the primary region of rotor wake-stator interaction is toward the outer portion of the blade, then it follows that much of the benefit from TEB should occur toward the rotor tip, suggesting that much of the observed full-span TEB benefit could be realized by just blowing the outer span of the rotor. Blowing just the outer portion of the blades would, of course, reduce blowing air requirements. Blockage plates were designed for Fan9 to block all but the outer 20 and $40 \%$ of the blowing airflow, thereby reducing the TEB blowing air requirements (see fig. 1). Figure 18 shows OAPWL levels for Fan9 with outer span TEB compared to 2.0\% full span blowing and the reference Fan1. Data were taken with the outer $20 \%$ of the Fan9 span blown at 0.64 and $0.84 \%$ of the bypass flow, respectively corresponding to full-span blowing rates of 2.0 and $2.6 \%$. Fan9 was also tested with the outer $40 \%$ span blown at flow rates of 0.81 and $1.07 \%$, respectively corresponding to full-span blowing rates of 1.5 and $2.0 \%$. The remaining inboard 60 or $80 \%$ of the Fan 9 span was $90 \%$ blocked, allowing for a residual TEB flow in an attempt to suppress possible vortex shedding near the blade root.

Blowing just part of the outer Fan9 span does not appear to reduce overall noise levels, and sometimes shows a noise increase over that of reference Fan1. In particular, blowing just the outer $20 \%$ span at either flow resulted in a measurable overall noise increase. The reason for this unexpected performance with outer span blowing is unclear. It is possible that the Fan9 inboard wake plays a significant role in the overall noise generation. Unfortunately, downstream hot film measurements, which can help to quantify the blowing performance, were not taken for the partial-span blowing configurations.

\section{Alternate-blade blowing}

Another way to economize on blowing air requirements is to blow only some of the rotor blades. This was investigated in the current test by blowing alternate Fan9 blades (full span), with blowing flow to the other blades blocked and trailing edge inserts on the blocked blades to complete the airfoil. The direct result of alternate-blade blowing is to reduce the blown rotor wakes which should show a somewhat reduced noise benefit relative to fullspan blowing of all blades. The blowing flow for the alternate-blade blowing was $1.0 \%$, half of the optimum full blowing. A secondary benefit of partial span blowing is a frequency redistribution of the tonal energy, resulting in 
rotor-stator tones based on the full blade count (nBPF) as well as half of that blade count ((n/2)BPF). This could result in more interaction tones with lower noise levels which might be more easily attenuated by duct acoustic liners. Reference 5 gives results for alternate blade blowing for the low speed/pressure ration NASA Glenn ANCF fan (ref. 5) where these (n/2)BPF tones are clearly evident.

Figure 19 shows the overall sound power level for TEB of all blades (at $2.0 \%$ flow) and alternate blades at a reduced flow. There is clearly some noise benefit from alternate-blade blowing, but significantly less than what was seen for the blowing all of the blades. The sound pressure level spectra of figure 20 ( $86 \%$ design fan speed, $50^{\circ}$ sideline emission angle) shows tone (nBPF) and broadband noise reductions with both alternate- and all-blade blowing. However, there was little evidence of additional (n/2)BPF interaction tones associated with alternate-blade blowing.

\section{Hot Film Rotor Wake Surveys}

As indicated earlier, the primary objective of the TEB rotor design effort was to partially fill in the mean blade wake downstream of the TEB fan relative to the baseline Fan1 rotor. Filling in the wake was expected to lead to reductions in rotor-stator interaction tone noise. Figure 21 provides some indication as to the extent to which this goal was achieved. This figure shows a comparison of total velocities measured downstream of the TEB fan (left) and Fan1 (right) at the upstream wake axial location (see fig. 6) with the two fans operating at the approach condition (5425 RPMc).

Both plots show average-passage data (i.e., the mean velocities measured downstream of the individual blade passages were folded into one passage and averaged as outlined in ref. 17). The average-passage flow is shown repeated in the plots in order to show the variations in the flow across the boundaries of the passage. The view is from downstream-looking-upstream; the fan blades rotate clockwise in this view. These plots clearly show that TEB is having a significant effect on the blade wakes. There appear, however, to be some regions along the span of the wake where the blowing is having a beneficial effect (thinner, shallower wakes than the baseline) and other regions where the blowing is having an adverse effect (wider, deeper wakes). The regions of adverse effect are shown as isolated "islands" of low momentum flow at discreet locations along the span of the blade wake. As illustrated in figure 1, the TEB flow emanated from five separate slots located along the trailing edge of Fan9. The islands of low momentum flow depicted in the TEB contour plots are believed to occur downstream of the narrow, solid regions along the blade trailing edge which separate the slots. The exact origin of these low momentum regions is unclear; however, they may result from the interaction of the three merging flow streams - the two flows emanating from the adjacent slots and the external flow passing over the blade.

More detailed comparisons of these mean blade wake flows are provided in figure 22. This figure shows six different sets of line plots (provided in parts A thru $\mathrm{F}$ of the figure). Each set corresponds to a different radial location in the flow; the locations are indicated by the solid lines overlaid on top of the contour plots shown above the line plots. In the line plots, the blue line shows the mean total velocity measured downstream of the TEB fan; the black line shows the distribution measured downstream of Fan1.

A) The plot provided in figure 22A shows data obtained in the outer region of the flow at a radius of 9.74 in. This plot indicates that at this location TEB provides a slight reduction in the mean velocity deficit relative to the baseline fan. This plot, however, is not typical of the data obtained in the outer regions of the fan bypass duct. As explained earlier, data were acquired at 50, equally-spaced radial locations along the span of the duct. Of the data obtained at the 19 outermost locations, the data provided here in figure 22A show the largest reduction in the mean velocity deficit. Surprisingly, most of the 19 other radial locations within this outer region show a deeper wake associated with the TEB fan.

B) The data of one such location is provided in figure 22B. This radial location corresponds to the location of one of the islands of low momentum flow mentioned in the discussion above. As can be seen in this plot, the mean wake deficit associated with TEB is deeper than that of the baseline rotor at this location.

C) Further inboard, the effects of blowing are more apparent. Figure $22 \mathrm{C}$ shows data obtained at a mid-span location away from the islands of low momentum flow. A significant reduction in the mean blade wake occurs at this location. This indicates that the blowing is more effective in the mid-span region of the TEB fan than it is in the outer region.

D) Figure 22D shows data obtained further inboard at about 35\% span. Once again the TEB appears to be effective at this location. 
E) Figure 22E shows data obtained at a radial location corresponding to the innermost island of low momentum flow. Unlike in the outer spans where such islands indicated a deeper wake for the TEB fan, here the deficit is roughly the same for TEB and Fan1.

F) Figure 22F shows data obtained at a location in-between the innermost island of low momentum flow and the hub surface. This plot clearly shows that at this inboard location the wake is being over-filled.

Overall, the above comparisons of wake data obtained at the approach condition indicate less-than expected blade wake filling in the outer regions of the blade wakes and more-than-expected inboard. This, in turn, suggests that less air was being blown out of the trailing edge in the tip region than expected, and that more air was being blown out at the inner radial locations than expected. The blade trailing edge flow distribution was established through "bench calibration tests" prior to the actual model tests in the wind tunnel. The wake distribution data shown in figure 22 were obtained after the model acoustic data were acquired.

As mentioned above, another reason for acquiring the hot-film data was to determine the extent to which TEB reduces the turbulence in the blade wakes. Figure 23 shows a comparison of total turbulent velocities (defined as the standard deviation of the total velocities measured at a location in the flow) measured downstream of the TEB rotor (left) and Fan1 (right) at the upstream axial measurement location with the fans operating at the approach condition $(5425 \mathrm{RPMc})$. The rotor tip clearance flow is a distinctive feature in each of these plots. This flow shows up clearly in the contours of each fan as the region of turbulent flow which exists along the outer case between the blade wakes. As shown, the turbulence level in the tip flow generated by the TEB fan is higher. This difference is thought to stem from a difference in the loading of the two fans. Although the TEB rotor was designed to have the same overall loading as Fan1, the span-wise loading distribution of the two fans was different. The TEB rotor was designed with more loading out at the tip of the blade and less loading inboard. This higher tip loading is thought to be responsible for the higher turbulence in the tip flow associated with the TEB fan due to additional tip leakage, although both rotors had the same $0.020 \mathrm{in}$. tip clearance.

The contours presented in figure 23 show higher turbulence levels downstream of the TEB rotor in the outer regions of the blade wakes, but significantly lower turbulence levels inboard. The higher levels in the outer regions of the blade wakes associated with the TEB rotor may result from 1) the higher blade loading in the tip region, and 2 ) the less-than expected level of TEB in this region suggested by the mean velocity measurements presented above. The span-wise trend (lower levels of turbulence associated with TEB with decreasing radius) correlates well with the apparent level of blowing along the blade span - as the blowing level increases the turbulence level decreases.

The line plots presented in figure 24 show some of this data in more detail. This figure shows comparisons of the total turbulent velocity distributions measured downstream of the two fans at four different radial locations. The magenta line shows the circumferential distribution of total turbulent velocity measured downstream of the TEB rotor; the black line shows Fan1 data. The span of the x-axis corresponds to one blade pitch.

A) The data presented in figure 24A correspond to a radial location which passes near the center of the tip flows developed by the two fans. This comparison shows higher turbulence levels downstream of the TEB rotor across the entire width of the passage. This suggests that the turbulence levels are higher not only in the tip flow but also in the blade wakes generated by the TEB fan at this outboard location.

B) The data shown in figure 24B were acquired at a radius of 10.06 in.. Here the turbulence level downstream of the two fans is essentially the same.

C) The data indicate that TEB generates less turbulence than Fan1 inboard of about $75 \%$ span. Figure $24 \mathrm{C}$ shows data obtained near $50 \%$ span. At this radial location the TEB rotor is generating significantly less turbulence than Fan1.

D) This trend of increasing benefit (reduced turbulence) with decreasing radius continues as the hub is approached. Figure 24D shows data obtained at about 25\% span. At this location the peak turbulent velocity associated with TEB is about half of that of Fan1.

These turbulent velocity comparisons indicate that TEB is very effective at reducing blade wake turbulence. This reduction is shown to correlate well with the level of blowing. In the tip region where the blowing was less-thanexpected very little, if any, reduction was achieved. In the mid-span and inner regions, however, where the level of blowing was higher, a significant reduction in the turbulence was achieved

\section{Concluding Remarks}

Rotor TEB has been identified in the literature as a possible mechanism for reducing turbofan bypass rotor wake and thereby reducing rotor wake-stator interaction noise levels. Earlier blade cascade and model fan experiments 
have confirmed the potential for TEB to fill in the rotor wake and possibly reduce fan noise. Benefits of TEB were further documented for a low speed/low pressure ratio model fan tested in a large anechoic chamber at the NASA Glenn Research Center. This report documents far field acoustic results for a more representative modern model turbofan with TEB. The blown rotor, designated "Fan9" was designed to be aerodynamically equivalent to the baseline "Fan1." Common flow path hardware were used for both fans. The model fans were tested at 0.10 tunnel Mach flight conditions in the NASA Glenn 9x15 LSWT, which provides an anechoic environment with far-field acoustic surveys. TEB configurations included full and partial span blowing over a range of blowing airflows as well as alternate blade blowing.

Full span TEB blowing was effective with a blowing airflow of about $2 \%$ of the bypass flow, showing reductions of both tone and broadband noise. Overall sound power level reductions of $2 \mathrm{~dB}$ were observed relative to noise levels for the baseline fan. Significant noise reductions of 5 or more $\mathrm{dB}$ were observed for the rotor-stator interaction tones, depending on tone order and fan speed. Broadband noise reductions up to $2 \mathrm{~dB}$ were also seen - especially at lower fan speeds. Blowing only portions of the outer blade span did not produce significant noise reductions, suggesting that more inboard portions of the rotor wake remain important noise sources.

Detailed measurements of the fan wake flow fields generated downstream of the baseline Fan1 rotor and the TEB fan (Fan9) with full-span blowing were obtained using hot-film probes at two different axial locations and at three different rotor speeds corresponding to the approach, cutback, and takeoff operating conditions of the two fans. Because of inaccuracies associated with using thermal anemometry to measure flow velocities in high-speed, compressible, non-isothermal flows, only low-speed approach condition data have been presented. The objective of the hot-film testing was to measure the velocity fields generated by the two different configurations (baseline Fan1 and TEB) so that detailed, quantitative evaluations could be made regarding 1) the ability of the TEB configuration to reduce the mean blade wake velocity deficit relative to the baseline Fan1 configuration and 2) the reduction in turbulence, if any, associated with blowing (TEB) versus no blowing (Fan1). The approach condition data presented herein indicate that the extent to which the TEB configuration reduced the mean blade wake velocity deficit relative to Fan1 varied with span-wise location; in the tip region this TEB configuration was not very effective at reducing the mean blade wake velocity deficit, in contrast, at the innermost radial locations the TEB resulted in overfilling of the mean wakes. These data suggest that the amount of air exiting the trailing edge was less-than-expected in the tip region and more-than-expected near the hub. Turbulence measurements made downstream of the two fans support this finding. These data show that the TEB configuration produced higher turbulence levels in the outer regions of the blade wakes, but lower levels inboard of about $75 \%$ span. At the innermost radial locations the turbulence levels with this TEB configuration were significantly lower than with the Fan1 configuration. In this region the highest turbulent velocities measured within the blade wakes with TEB were about half of those measured with Fan1. This reduction in blade wake turbulence may be responsible for the reduction in broadband noise indicated in the acoustic measurements.

\section{References}

1. Corcoran, T.E., "Control of the Wake from a Simulated Blade by Trailing-Edge Blowing," Masters Thesis, Lehigh University, Bethlehem, Penn., Jan. 1992.

2. Brookfield, J.M, and Waitz, I.A., "Trailing Edge Blowing for Reduction of Turbomachinery Fan Noise," AIAA-98-2321, 1998; AIAA Journal of Propulsion and Power, Vol. 16, No. 1, Jan-Feb. 2000, pp. 57-64.

3. Rao, N.M, "Reduction of Unsteady Stator Rotor Interaction by Trailing Edge Blowing Using MEMS Based Microvalves," Masters Thesis, Virginia Polytechnic Institute and State University, Blacksburg, Va., 1999.

4. Heidelberg, L.J., Hall, D.G., Bridges, J.E., Nallasamy, M., "A Unique Ducted Fan Test Bed for Active Noise Control and Aeroacoustics Research," NASA TM-107213/AIAA-96-1740, May, 1996.

5. Loew, R.A., Lauer, J.T., McAllister, J., and Sutliff, D.L., "The Advanced Noise Control Fan," AIAA-20063150, NASA/TM-2006-214368, 2006.

6. Halasz, C., Arntz, D., Burdisso, R., and Ng, W., "Fan Flow Control for Noise Reduction Part 1: Advanced Trailing Edge Blowing Concepts," AIAA-2005-3025, 2005.

7. Langford, M.D., Minton, C.M., Ng, W.F., Estevadeordal, J., and Burdisso, R.A., "Fan Flow Control for Noise Reduction Part 2: Investigation of Wake-Filling Techniques," AIAA-2005-3026, 2005.

8. Langford, M.D., Minton, C., Ng, W., Burdisso, R.A., and Halasz, C., "Fan Flow Control for Noise Reduction Part 3: Rig Testing of Optimal Design," AIAA-2005-3027, 2005.

9. Sutliff, D.L, Tweedt, D.L., Fite, E.B., and Envia, E., "Low-Speed Fan Noise Reduction with Trailing Edge Blowing," Aeroacoustics Vol. 1, No. 3, 2002, pp. 275-305. 
10. Dahl, M.D., and Woodward, R.P., "Comparison Between Design and Installed Acoustic Characteristics of the NASA Lewis 9- by 15-Foot Low Speed Wind Tunnel Acoustic Treatment," NASA TP-2996, Apr. 1990.

11. Dahl, M.D., and Woodward, R.P., "Background Noise Levels Measured In the NASA Lewis 9- by 15-Foot Low Speed Wind Tunnel," NASA TP-3274, Nov. 1992.

12. Woodward, R.P., and Dittmar, J.H., "Background Noise Levels Measured in the NASA Lewis 9- by 15- Foot Low-Speed Wind Tunnel," NASA TM-106817/AIAA-95-0720, 1995.

13. Chestnutt, D., "Flight Effects of Fan Noise," NASA CP-2242, January, 1982

14. Jeracki, R.J., "Comprehensive Report of Fan Performance from Duct Rake Instrumentation on 1.294 Pressure Ratio, 806 ft/sec Tip Speed Turbofan Simulator Models," NASA/TM-2006-213863, Feb. 2006.

15. Tyler, J.M. and Sofrin, T.G., "Axial Flow Compressor Noise Studies," SAE Trans. vol. 70, 1962, pp. 309-332.

16. Fite, E.B., Woodward, R.P., and Podboy, G.G., "Effect of Trailing Edge Flow Injection on Fan Noise and Aerodynamic Performance," AIAA-2006-2844, 2006.

17. Podboy, G.G., Krupar, M.J., Helland, S.M., and Hughes, C.E., "Steady and Unsteady Flow Field Measurements Within a NASA 22-Inch Fan Model," AIAA-2002-1033, July 2003.

TABLE 1.-FAN DESIGN CHARACTERISTICS FOR ADP FAN1

\begin{tabular}{lc}
\hline \hline Pressure ratio & \\
Takeoff & 1.284 \\
*Cruise & 1.294 \\
Cutback & 1.209 \\
Approach & 1.077 \\
Corrected tip speed, ft/s & \\
Takeoff & 840 \\
Cruise & 806 \\
Cutback & 723 \\
Approach & 480 \\
Corrected rpm & \\
Takeoff & 8750 \\
Cruise & 8400 \\
Cutback & 7525 \\
Approach & 5425 \\
Bypass ratio-cruise & 13.3 \\
Blade number & 18 \\
Vane number & 45 \\
Hub/tip ratio & 0.426 \\
Passive core (no rotor) & 63 core vanes \\
Bypass rotor-stator spacing & 1.8 axial fan mid-span chords \\
\hline *Fan1 had manually-adjustable blade setting angles. The blades were set at $-9^{\circ}$ for the trailing edge \\
blowing tests, as designated for the three rating conditions (takeoff, cutback, approach). However, a \\
blade setting angle of $0^{\circ}$ is used for the cruise condition.
\end{tabular}

TABLE 2.-ROTOR BLOWING CONFIGURATIONS

\begin{tabular}{lccccc}
\hline \hline \multicolumn{1}{c}{ Rotor } & Bypass nozzle & \% Span blowing & $\begin{array}{c}\text { Blowing rate } \\
\text { \% bypass flow) }\end{array}$ & $\begin{array}{c}\text { Blowing temp. } \\
\text { (hot/cold) }\end{array}$ & $\begin{array}{c}\text { Acoustic } \\
\text { barrier wall }\end{array}$ \\
\hline **Ref. fan1 & Flight & N.A. & N.A. & N.A. & No, yes \\
Blown fan 9 & Flight & Full & $2.0 \%$ & Hot & No \\
Blown fan 9 & Flight $+1.45 \%$ & Full & $2.0 \%$ & Cold & No \\
**Blown fan 9 & Flight $+1.45 \%$ & Full & $0.0,1.0,1.5,2.0,2.5 \%$ & Hot & No \\
Blown fan 9 & Flight $+1.45 \%$ & Full & $2.0 \%$ & Hot & Yes \\
**Blown fan 9 & Flight $+1.45 \%$ & Outer 40\% & $0.81,1.07 \%$ & Hot & No \\
Blown fan 9 & Flight $+1.45 \%$ & Outer 20\% & $0.64,0.84 \%$ & Hot & No \\
Blown fan 9 & Flight $+1.45 \%$ & Full, alt. blades & $1.0 \%$ & Hot & No \\
\hline \hline
\end{tabular}

**Hot film surveys were taken downstream of the rotor for these configurations. Surveys were taken at 0.0 and $2.0 \%$ full-span blowing; $1.07 \%$ blowing for outer $40 \%$ blowing. 


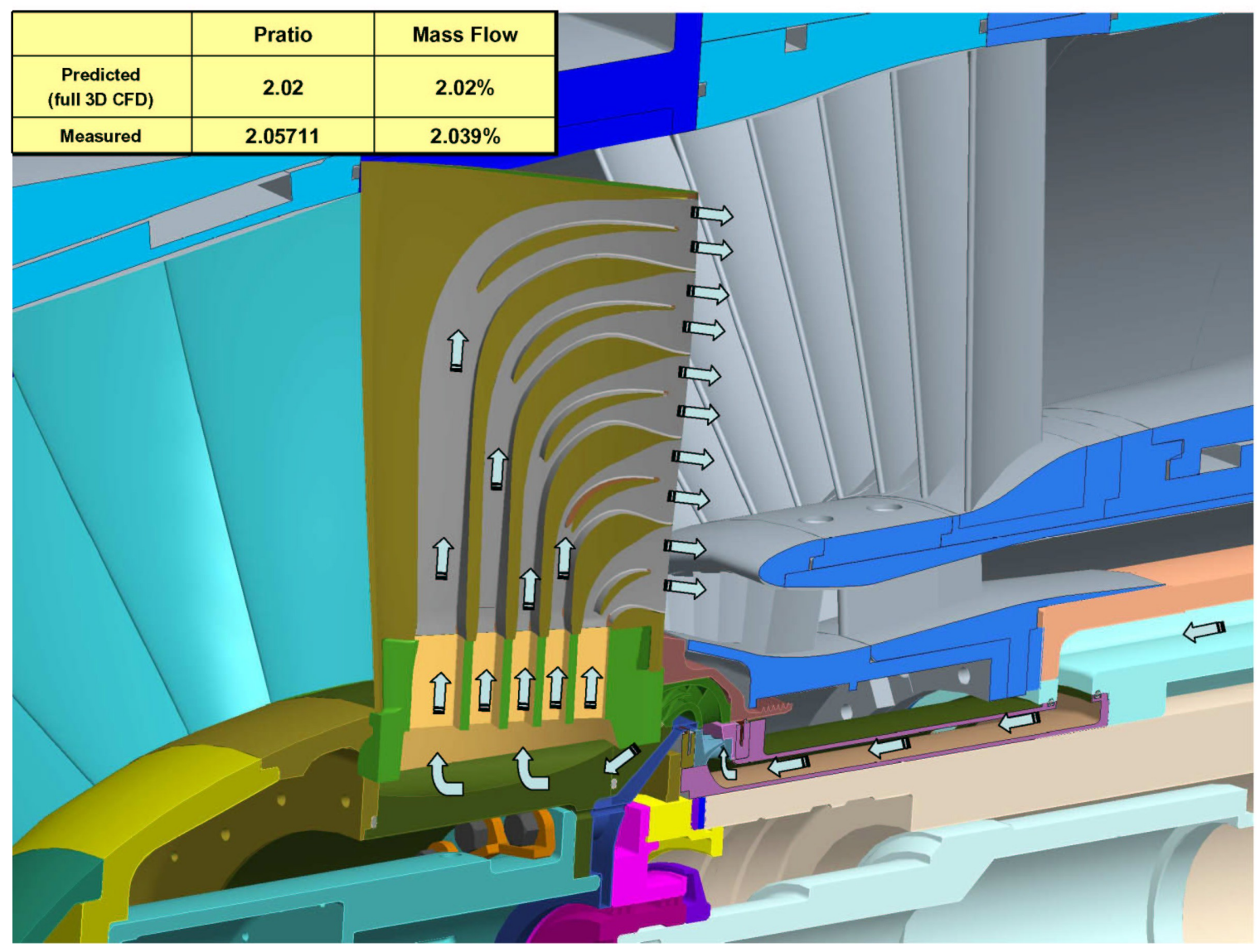

Figure 1.-Trailing edge air injection and supply.

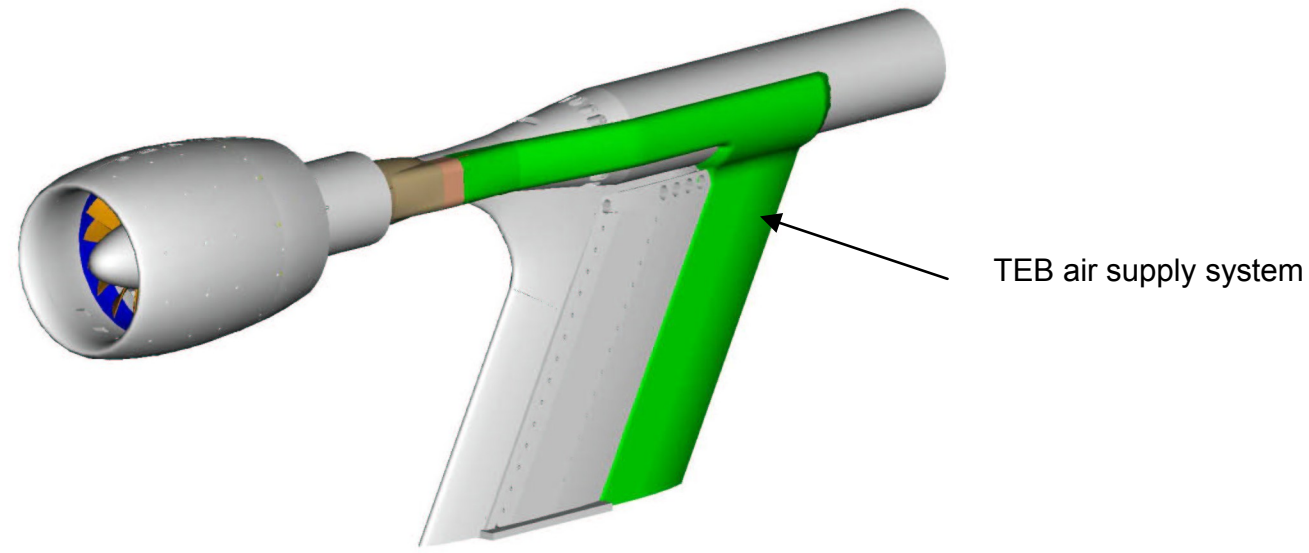

Figure 2.-Model in far-field acoustic configuration. 


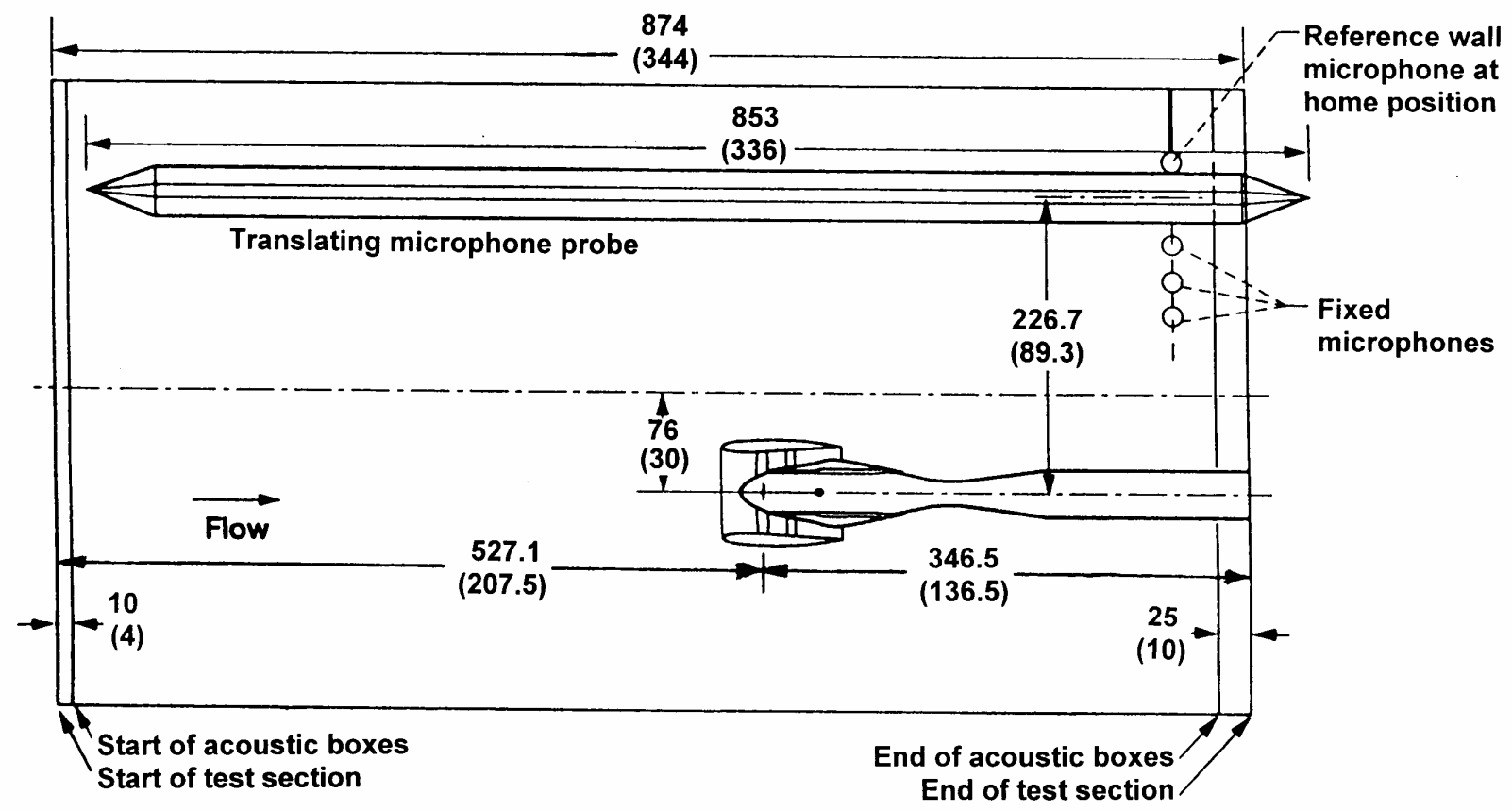

Figure 3.- Sketch of the model fan installed in the 9- by 15-Foot Low Speed Wind Tunnel. Far-field acoustic data were acquired with a translating microphone probe and aft fixed microphones. (Dimensions in $\mathrm{cm}$ (in.)).

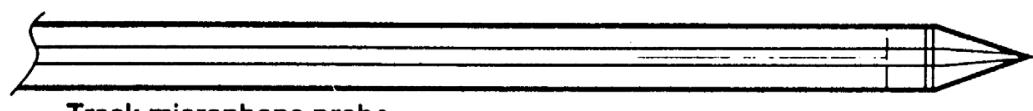

Track microphone probe

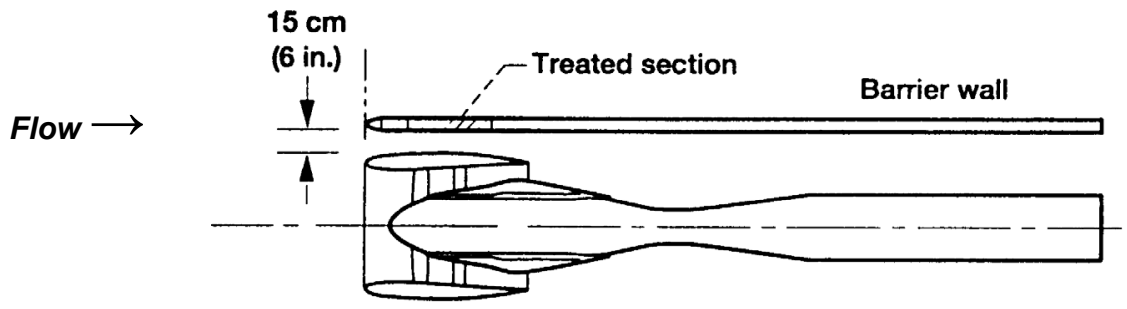

Figure 4.-Sketch showing location of acoustic barrier wall relative to model fan (Dimensions are $\mathrm{cm}$ (in.)). 


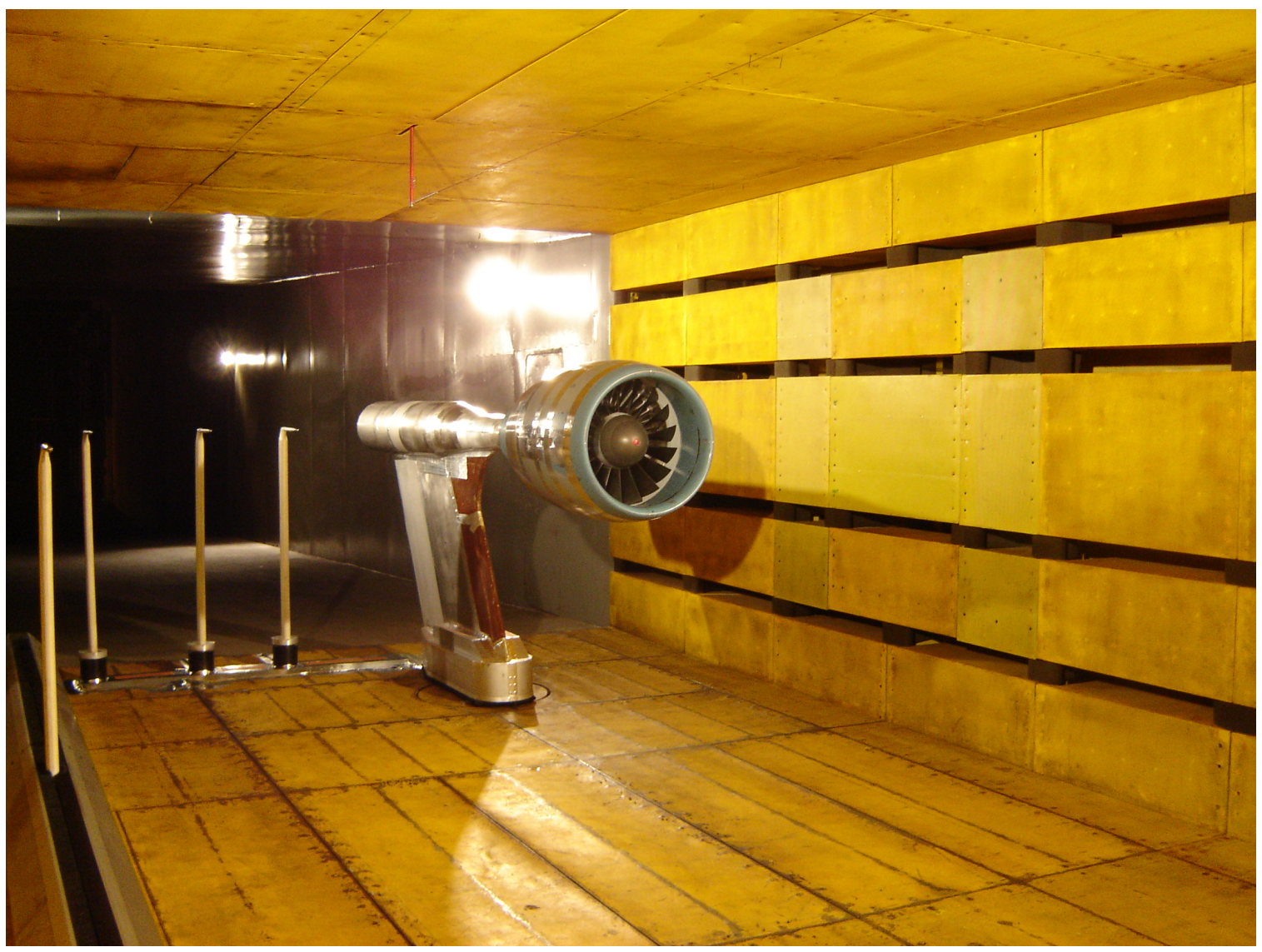

Figure 5.-Photograph of the model fan installed in the NASA Glenn 9x15 LSWT.

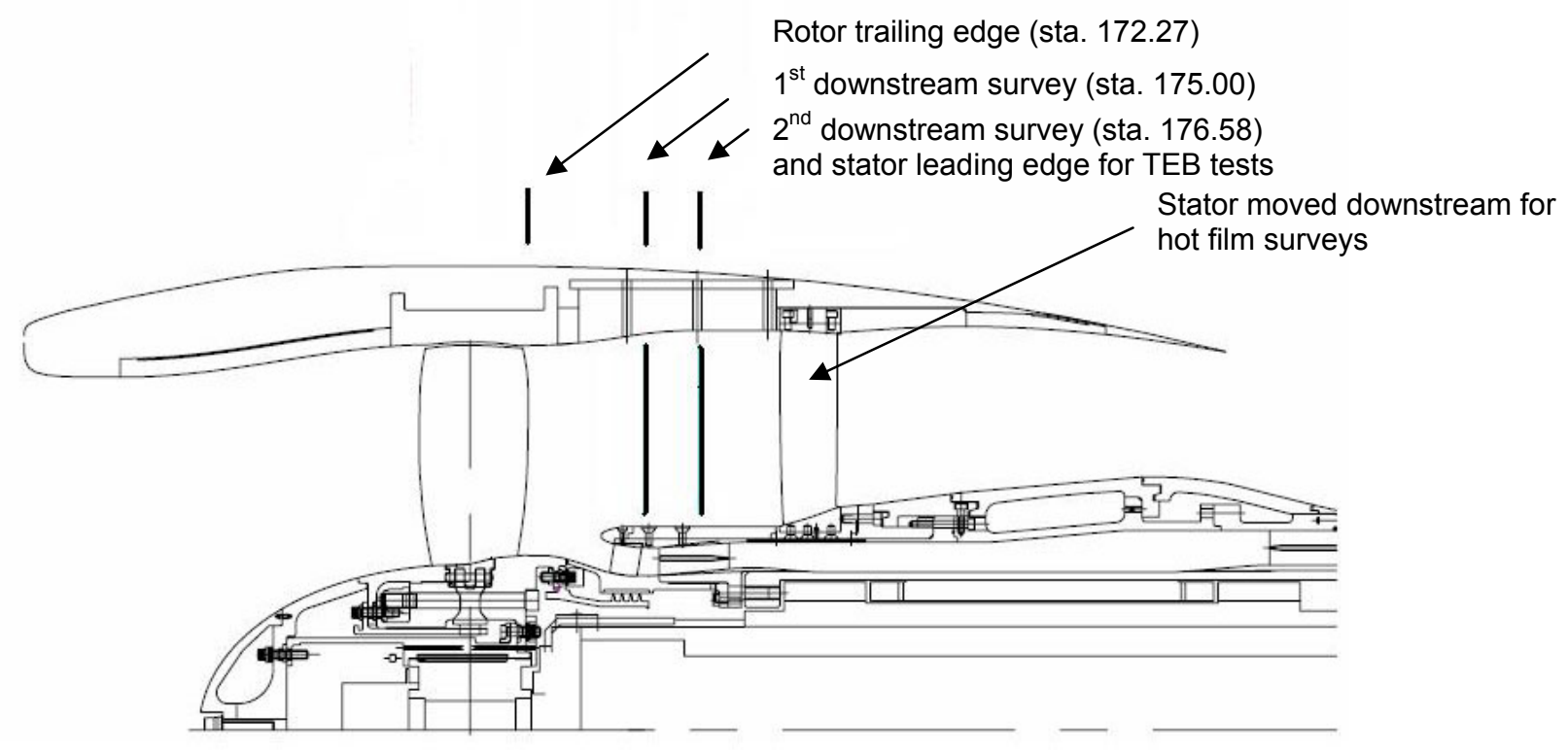

Figure 6.-Location of hot film surveys (station axial locations in inches). 


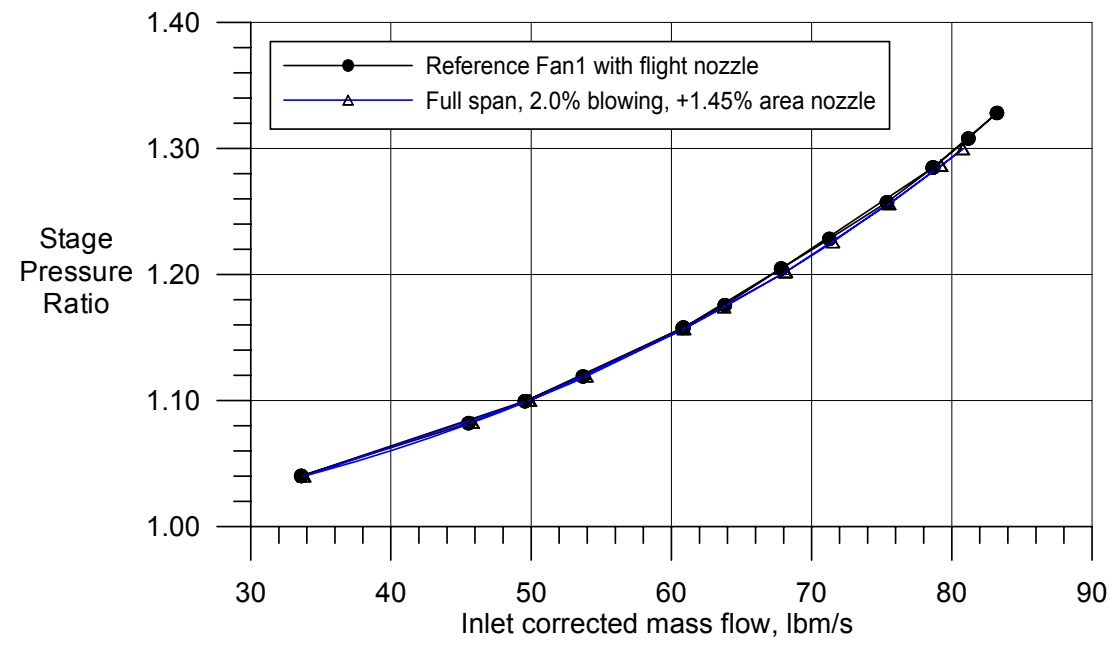

Figure 7.-Fan stage operating map comparing reference Fan1 with baseline nozzle and Fan9 with $2.0 \%$ blowing and oversized nozzle.

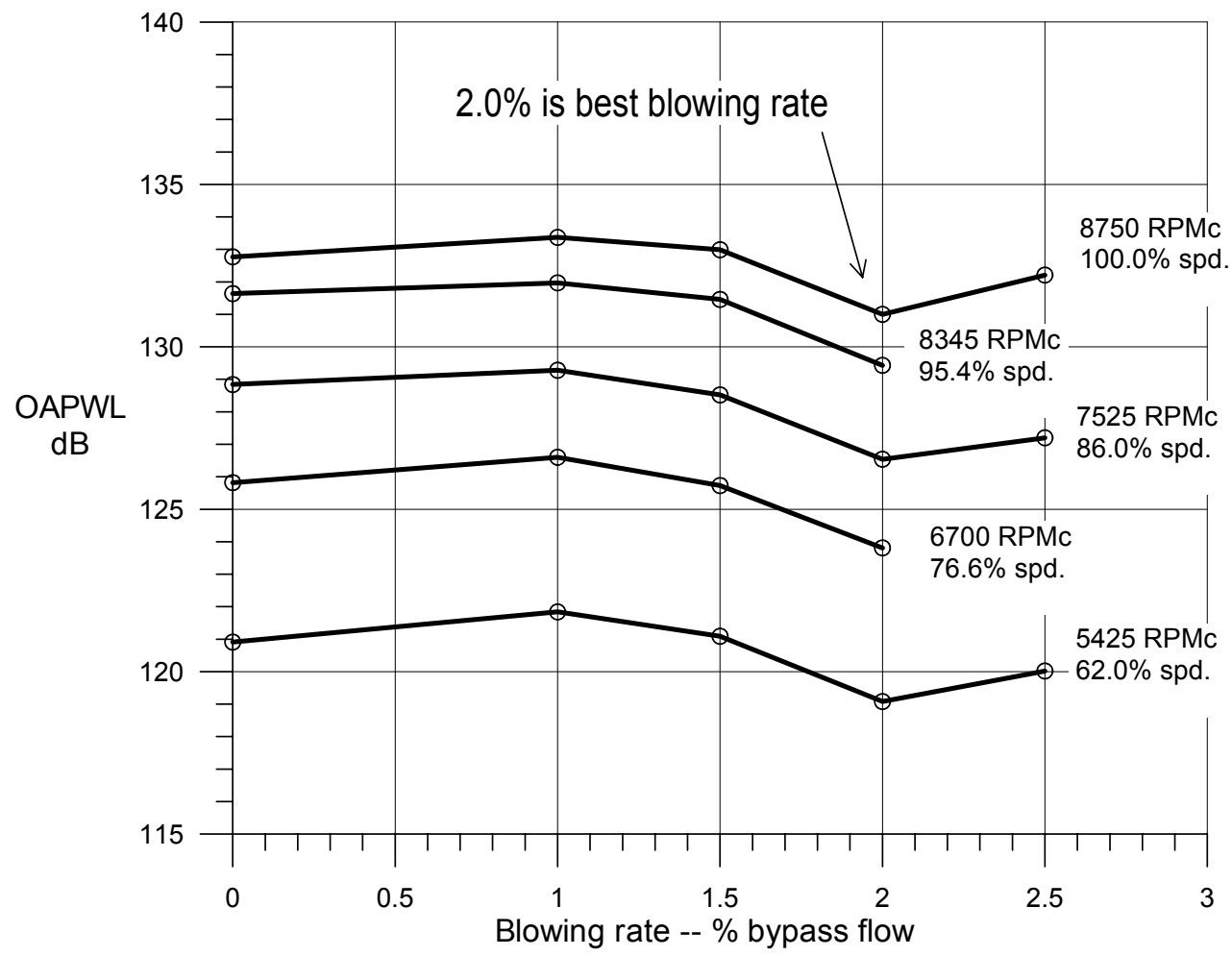

Figure 8.-Effect of various full-span blowing rates on the overall sound power level. 


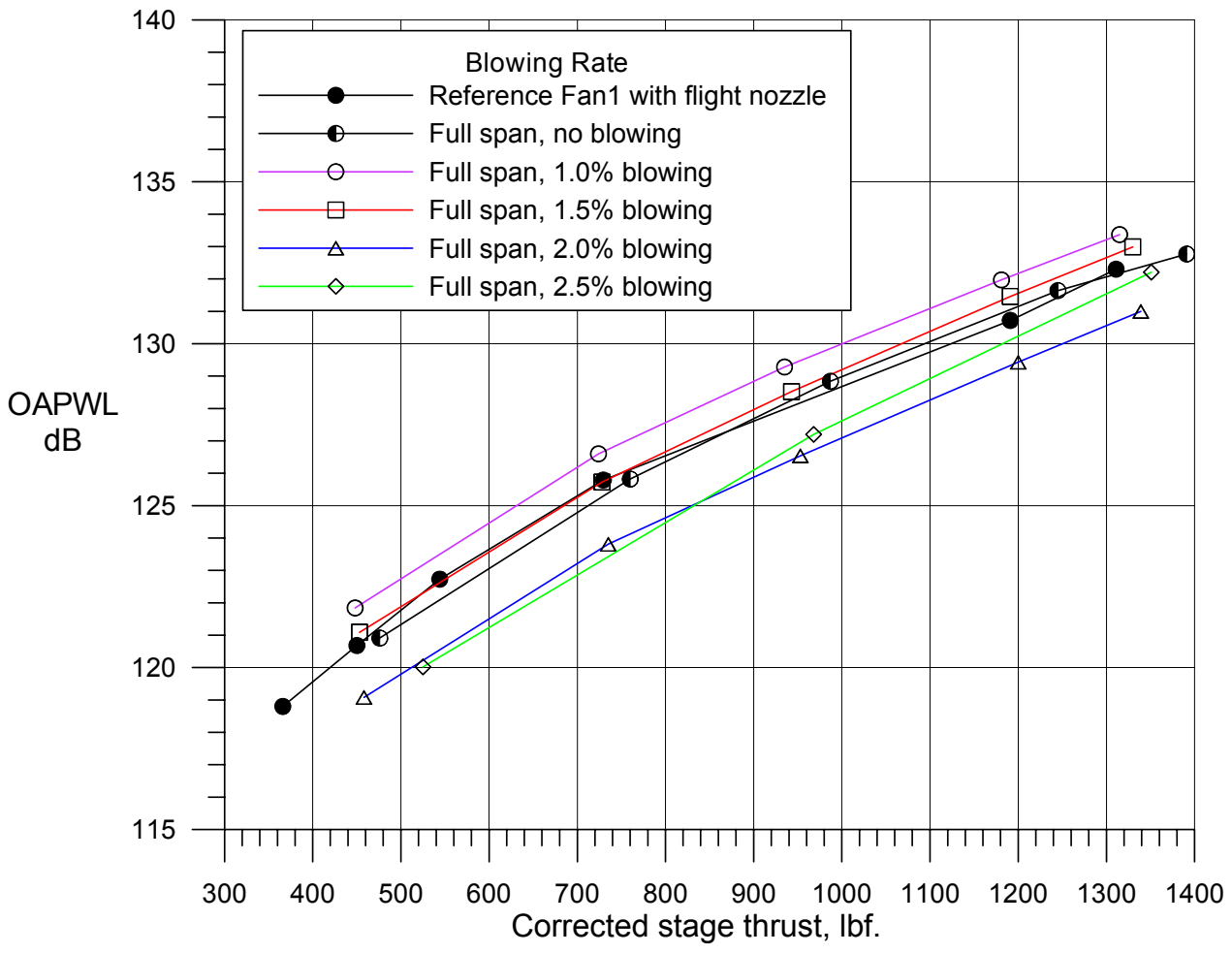

Figure 9.-OAPWL as a function of corrected stage thrust for several full-span blowing rates. 


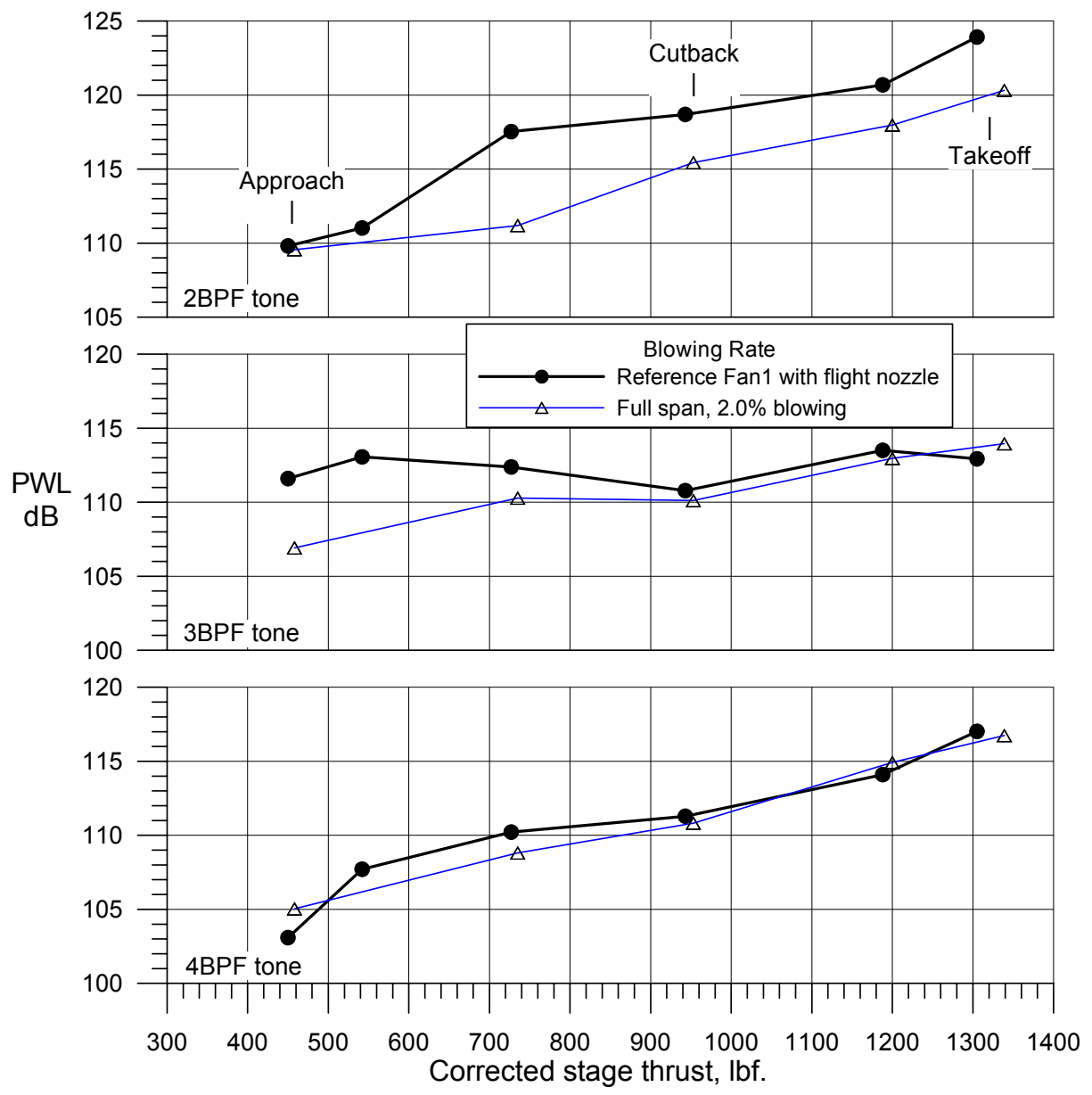

Figure 10.-Effect of 2.0\% TEB on the first three rotor-stator tone orders. 


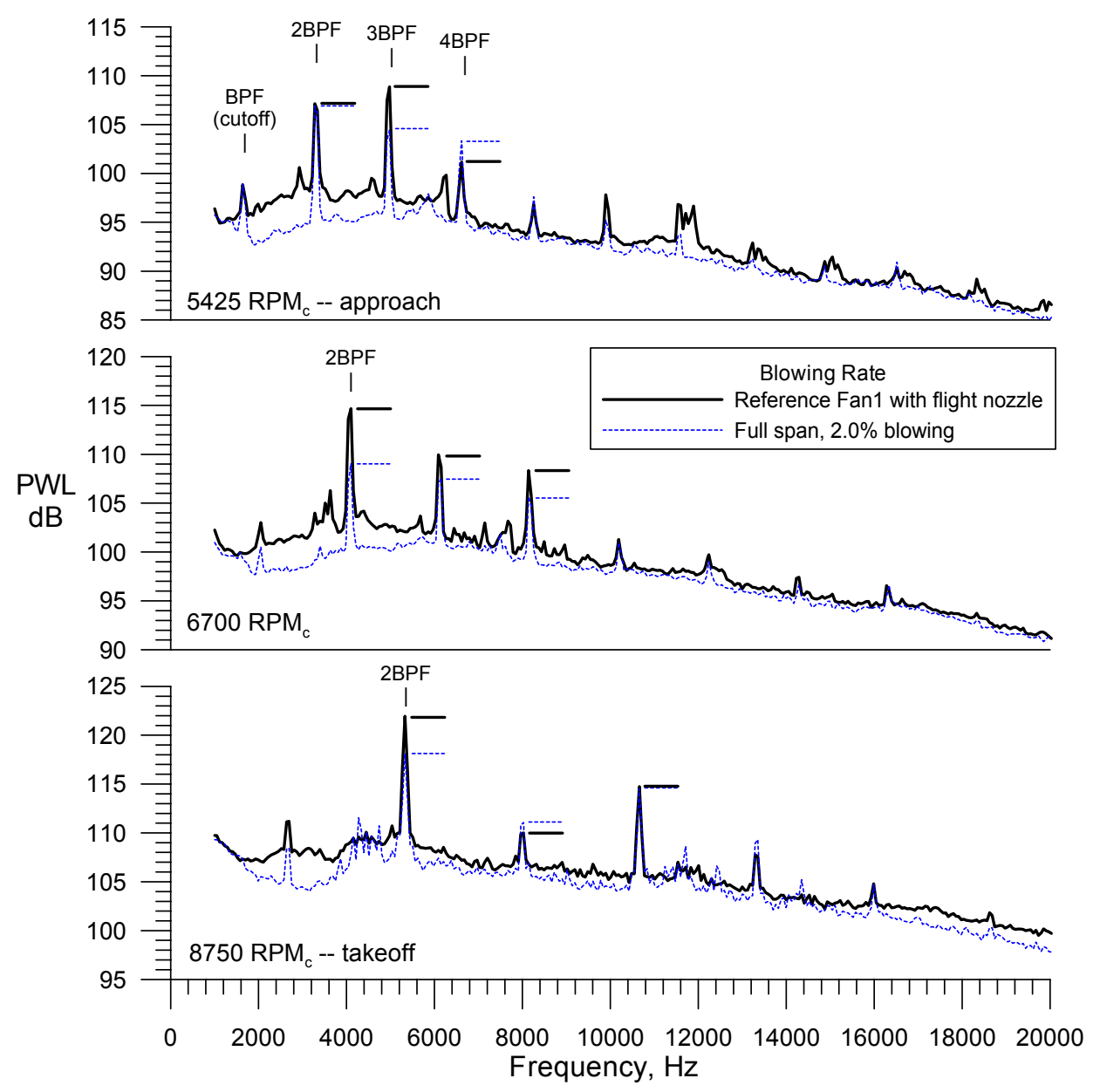

Figure 11.-PWL spectra at three fan speeds showing noise reductions associated with Fan9 2.0\% TEB (59 Hz bandwidth). 


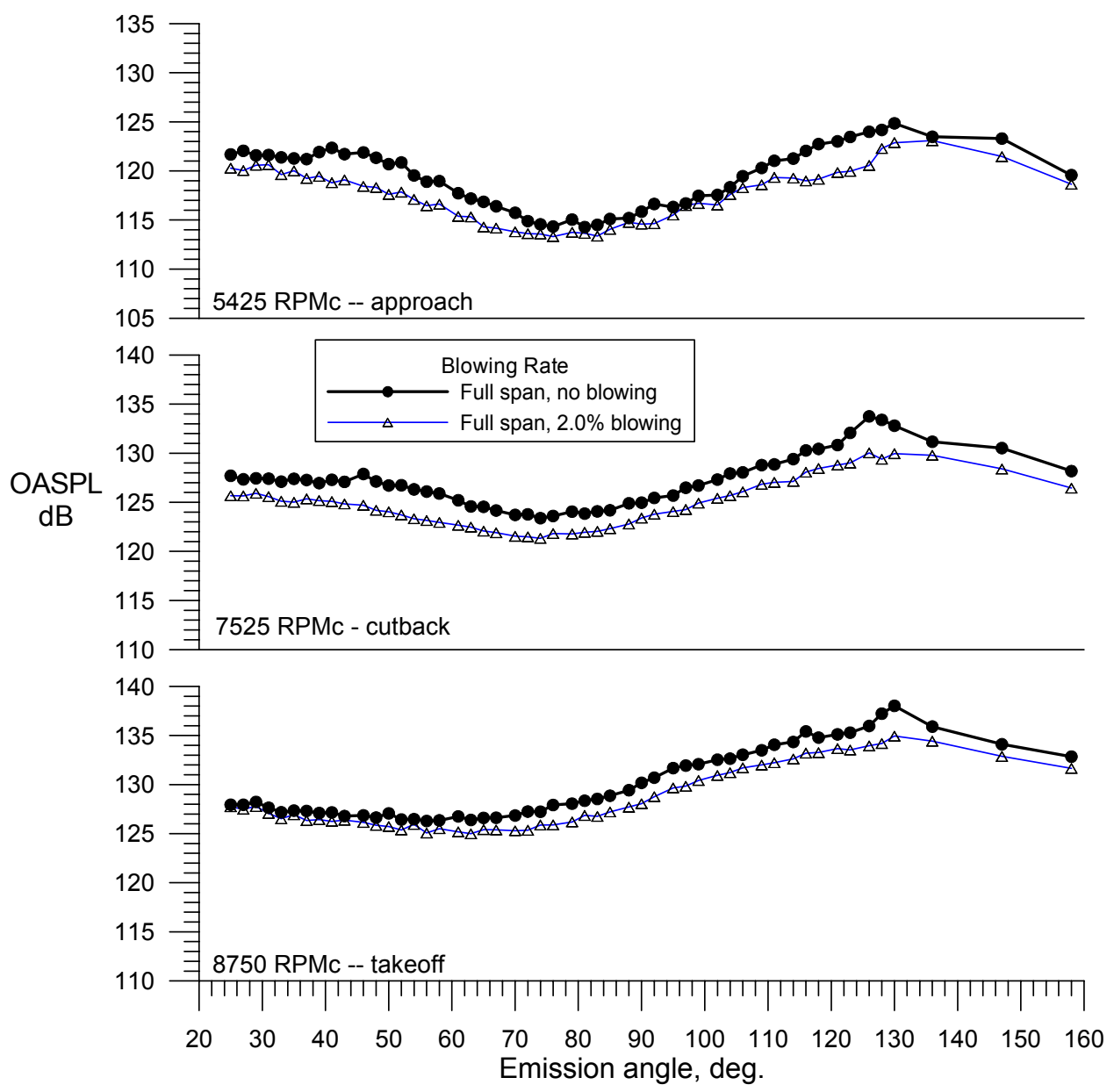

Figure 12.-Overall sound pressure level directivities for three fan speeds ( $1 \mathrm{ft}$ lossless, $1 \mathrm{kHz}$ to $20 \mathrm{kHz}$ ) 


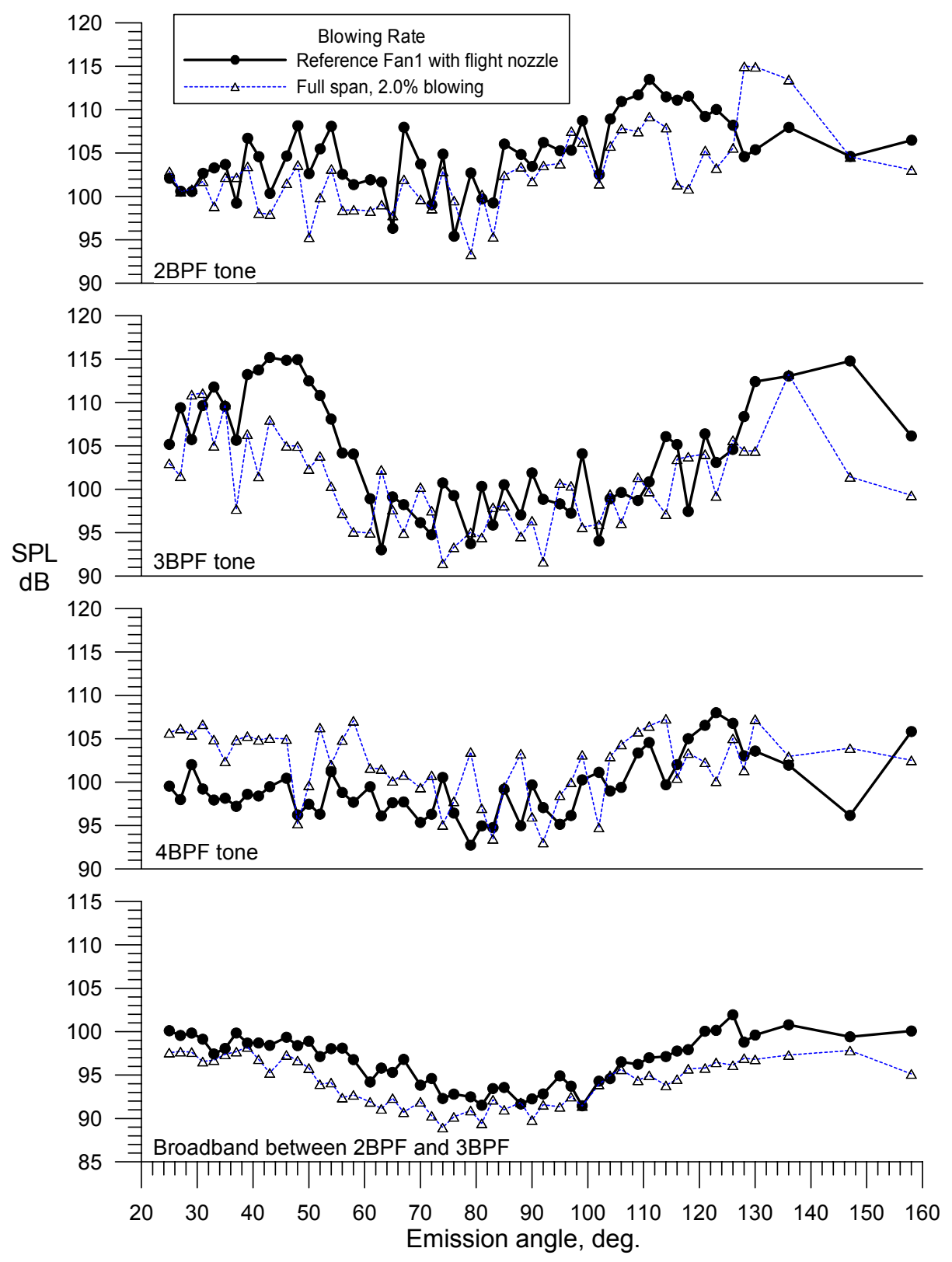

Figure 13.-Sound pressure level directivities at 5425 RPMc (62\% design fan speed (designated approach), $1 \mathrm{ft}$ lossless, $59 \mathrm{~Hz}$ bandwidth). 


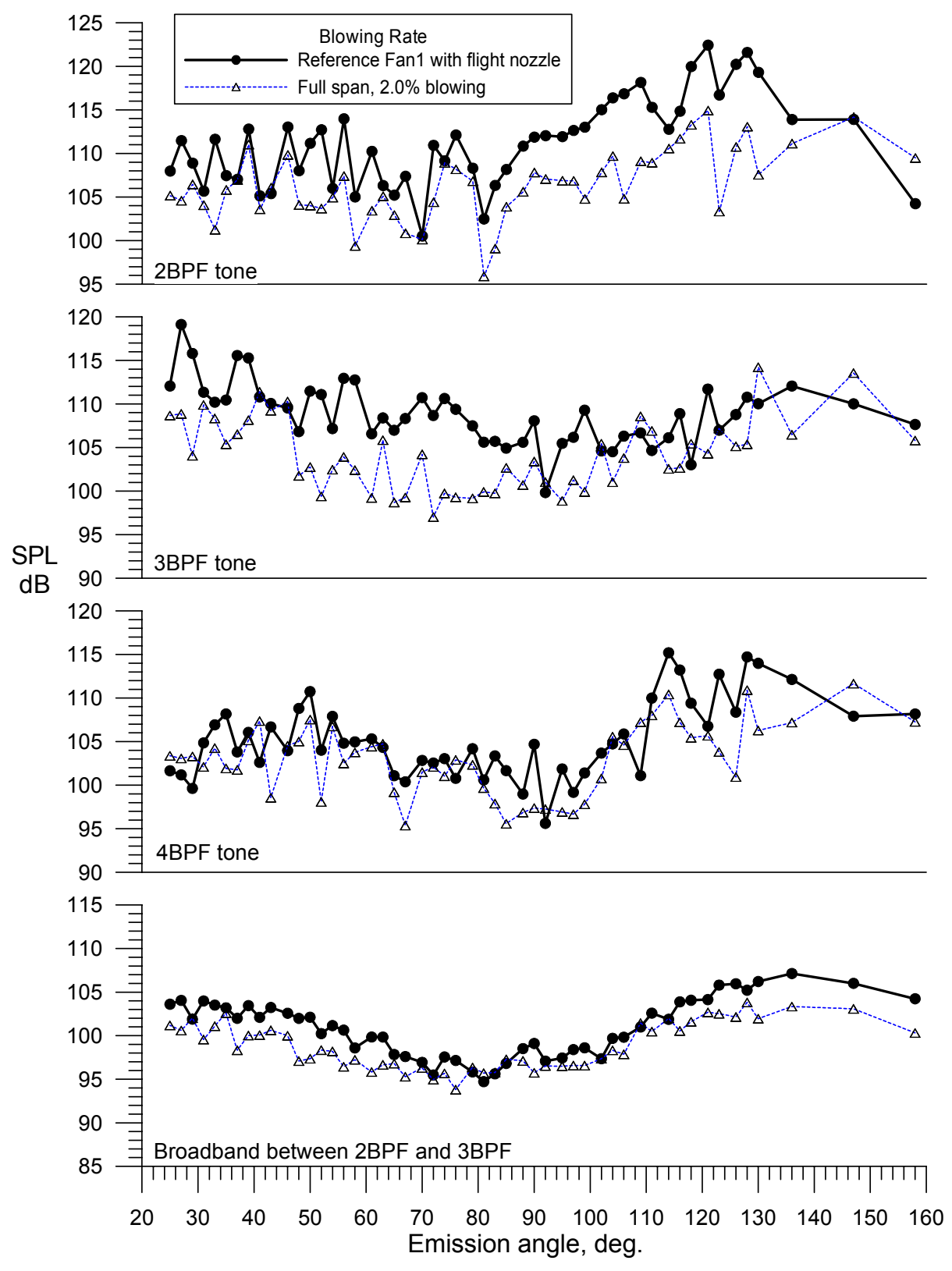

Figure 14.-Sound pressure level directivities at 6700 RPMc

(76.6\% design speed, $1 \mathrm{ft}$ lossless, $59 \mathrm{~Hz}$ bandwidth). 


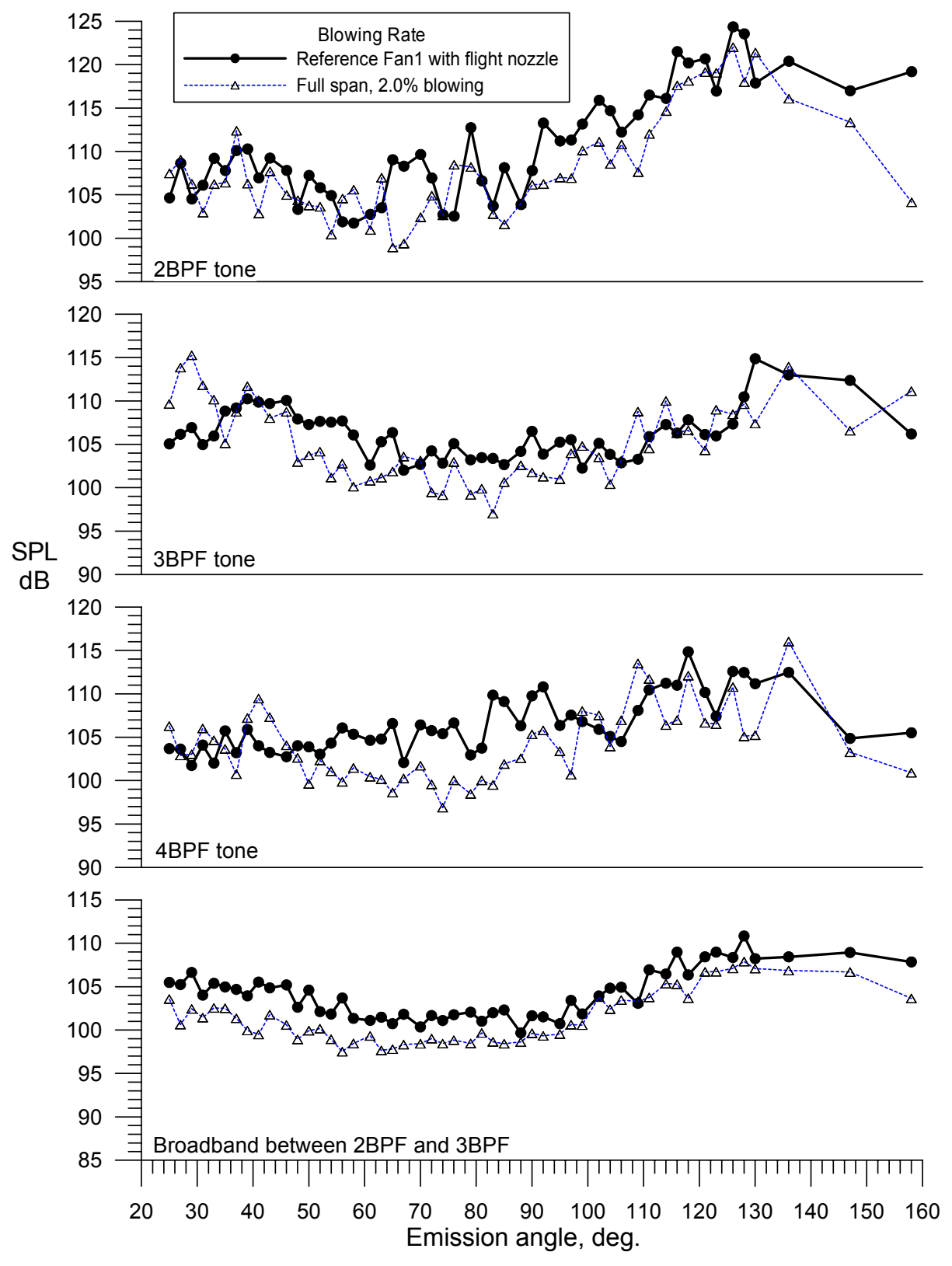

Figure 15.--Sound pressure level directivities at 7525 RPMc (86\% design speed (designated cutback), $1 \mathrm{ft}$ lossless, $59 \mathrm{~Hz}$ bandwidth). 


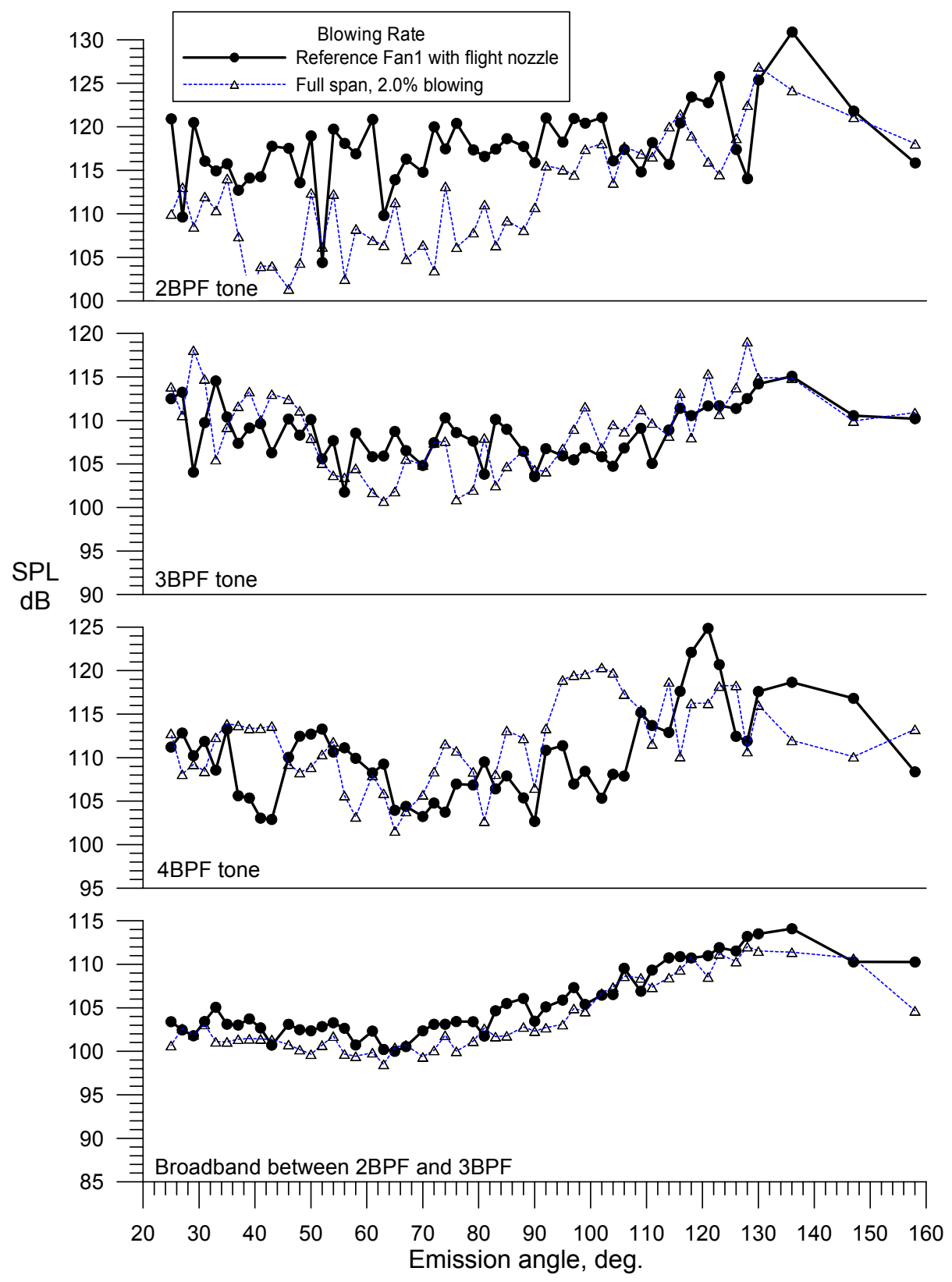

Figure 16.-Sound pressure level directivities at 8750 RPMc (design fan speed (designated takeoff), $1 \mathrm{ft}$ lossless, $59 \mathrm{~Hz}$ bandwidth). 


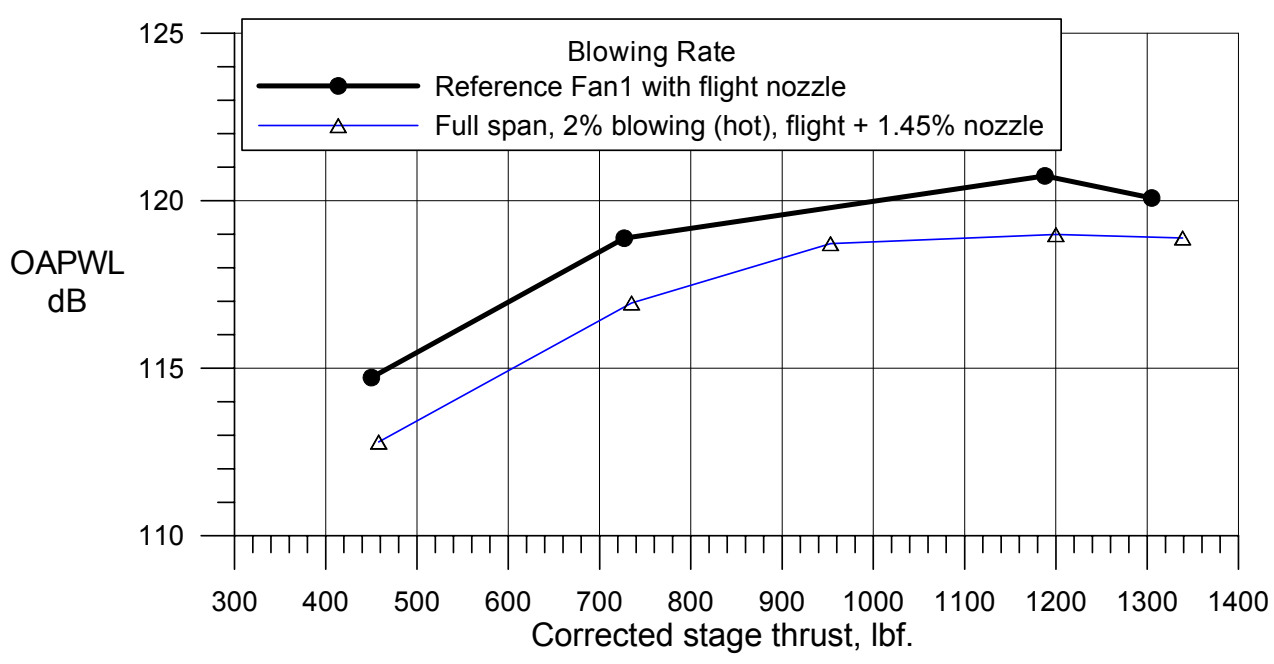

Figure 17.-OAPWL as a function of corrected stage thrust with the acoustic barrier wall present.

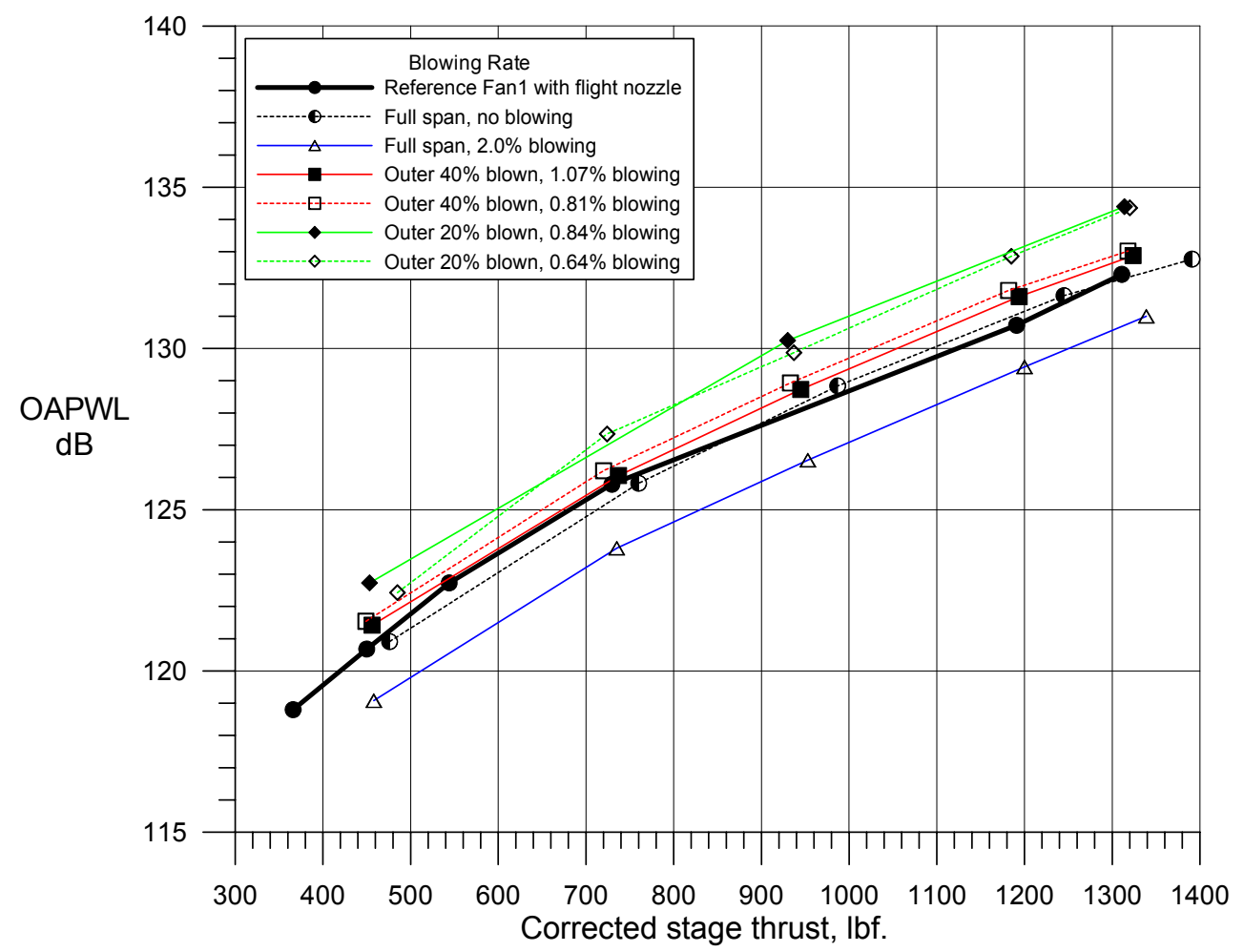

Figure 18.-OAPWL as a function of corrected stage thrust for partial-span blowing. 


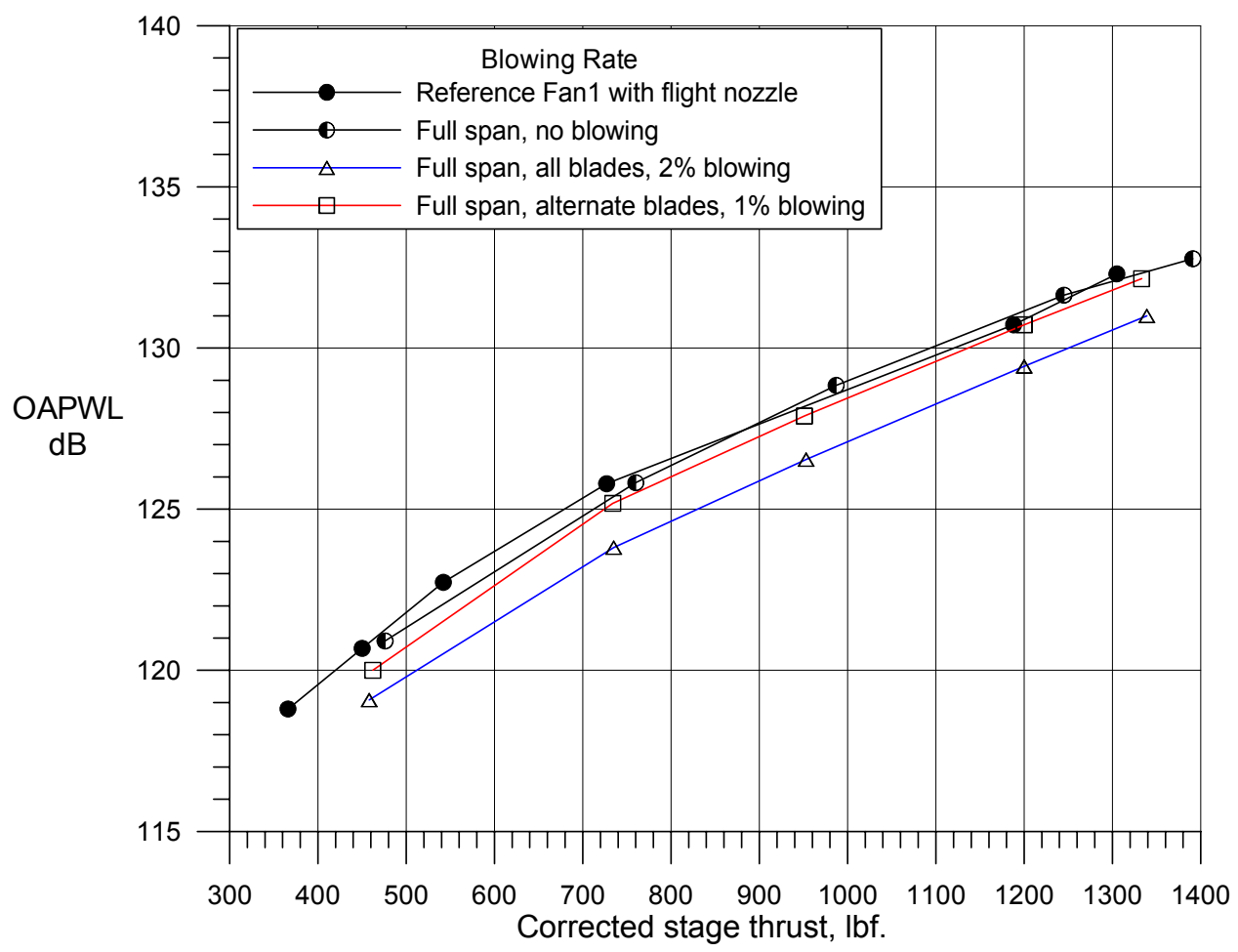

Figure 19.-OAPWL as a function of corrected stage thrust, blowing alternate blades at $2.0 \%$ flow rate.

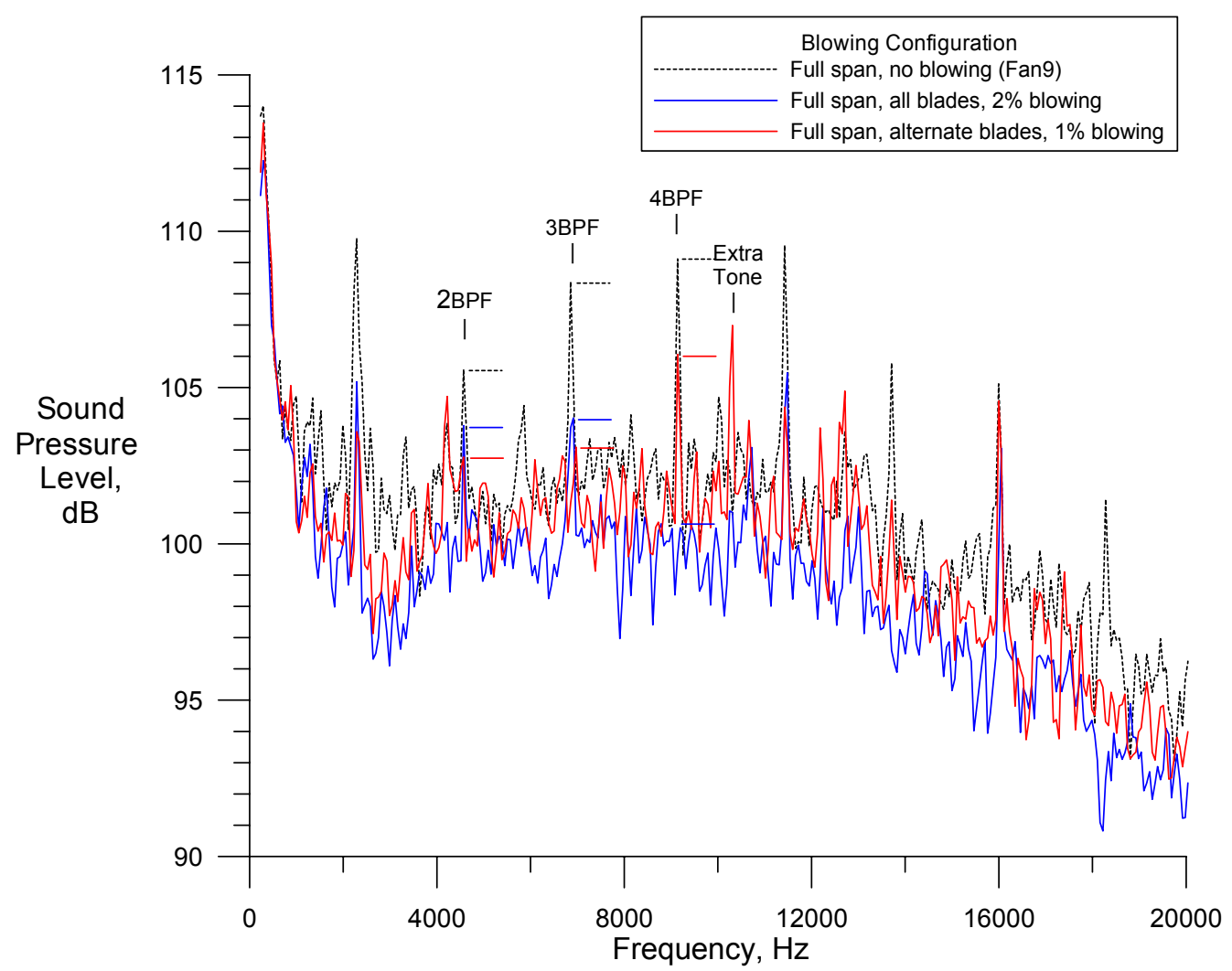

Figure 20.- Sound pressure level spectra at $50^{\circ}$ emission angle at 7525 RPMc (86\% design speed, (designated cutback), $1 \mathrm{ft}$ lossless, $59 \mathrm{~Hz}$ bandwidth). 

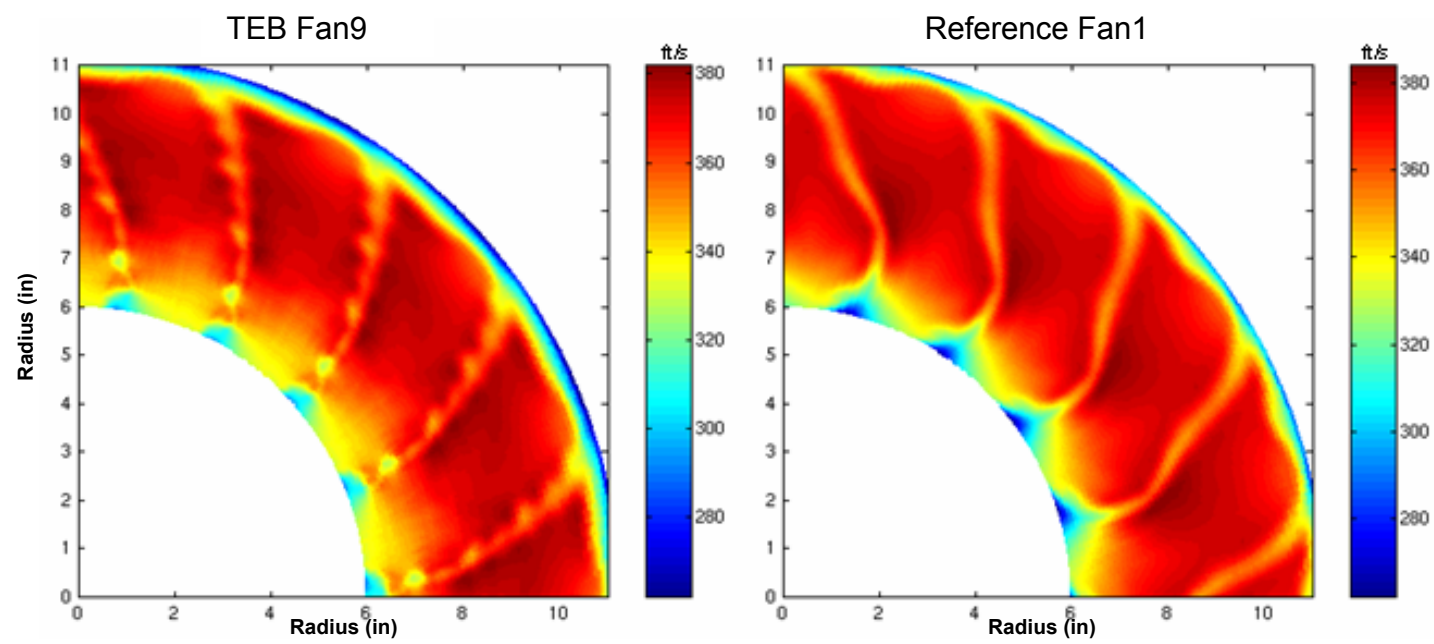

Figure 21.-Comparison of total velocities measured downstream of Fan9 with TEB (left) and Fan1 (right).

TEB Fan9

Reference Fan1

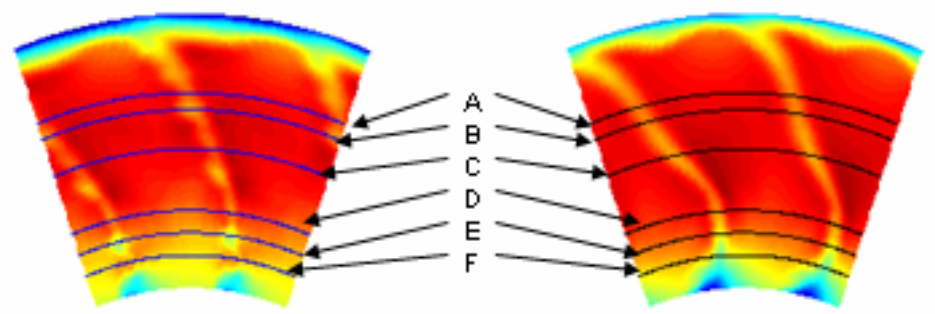

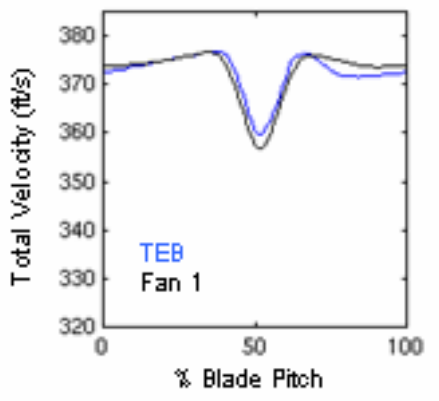

A) $\mathrm{r}=9.74^{\prime \prime}$

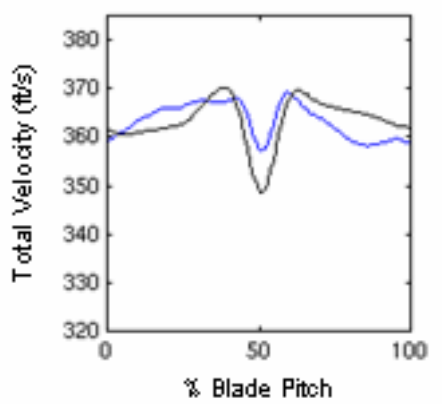

D) $\mathrm{r}=7.4 \mathrm{~g}^{\prime \prime}$

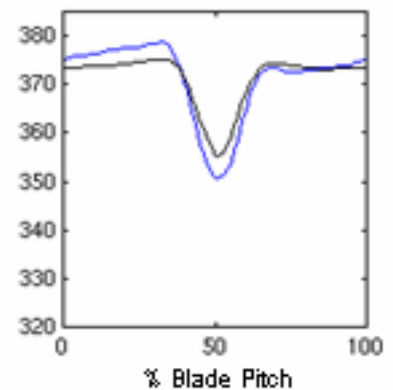

B) $r=9.42 "$

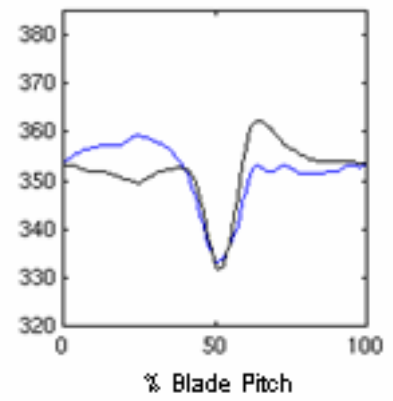

E) $r=7.06^{\prime \prime}$

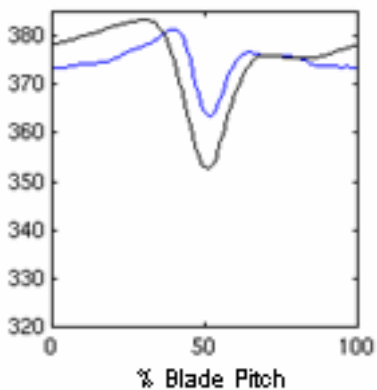

C) $\mathrm{r}=8.67 "$

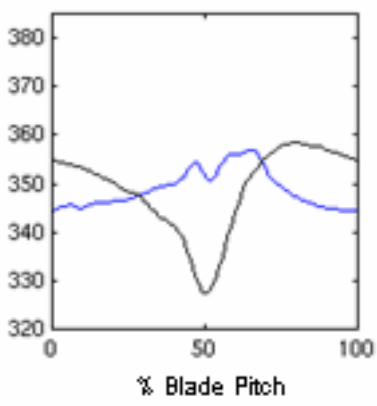

F) $r=6.63^{\prime \prime}$

Figure 22.-Comparison of blade wakes measured downstream of Fan1 (black) and Fan9 with TEB (blue). 

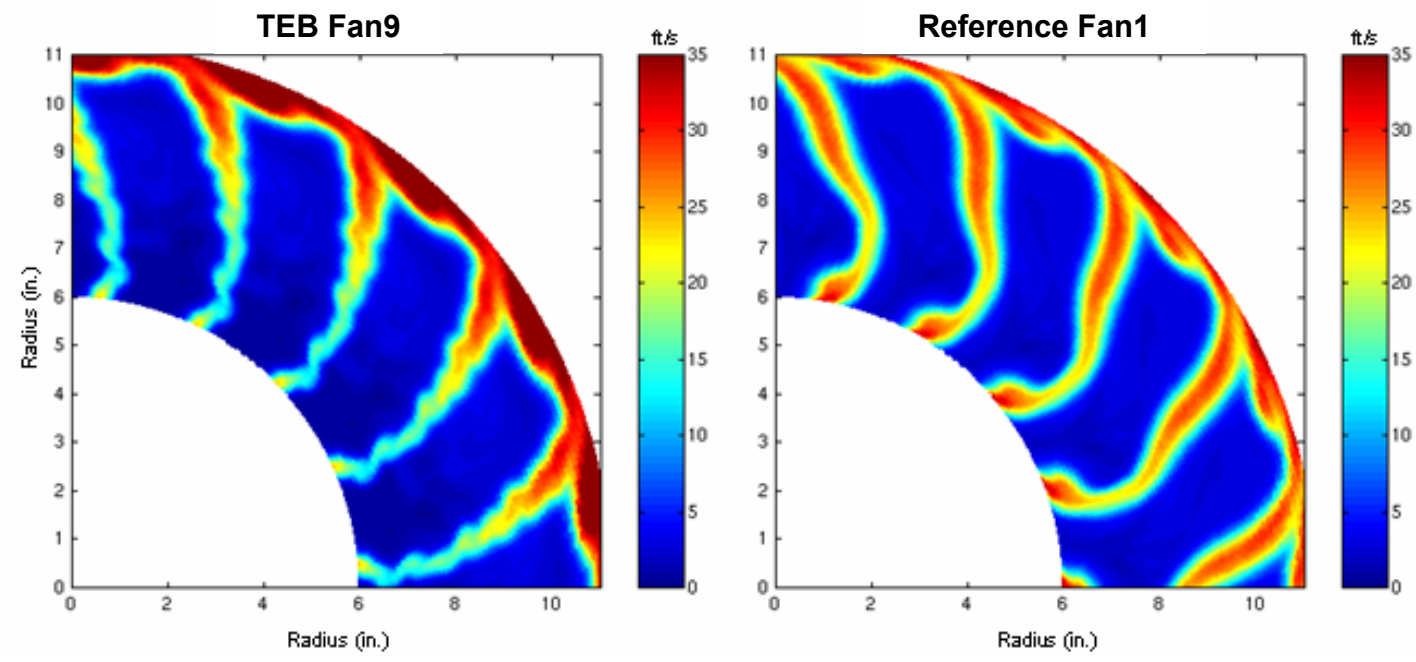

Figure 23.-Comparison of turbulent velocities measured downstream of Fan9 with TEB (left) and Fan1 (right).

TEB Fan9

Reference Fan1
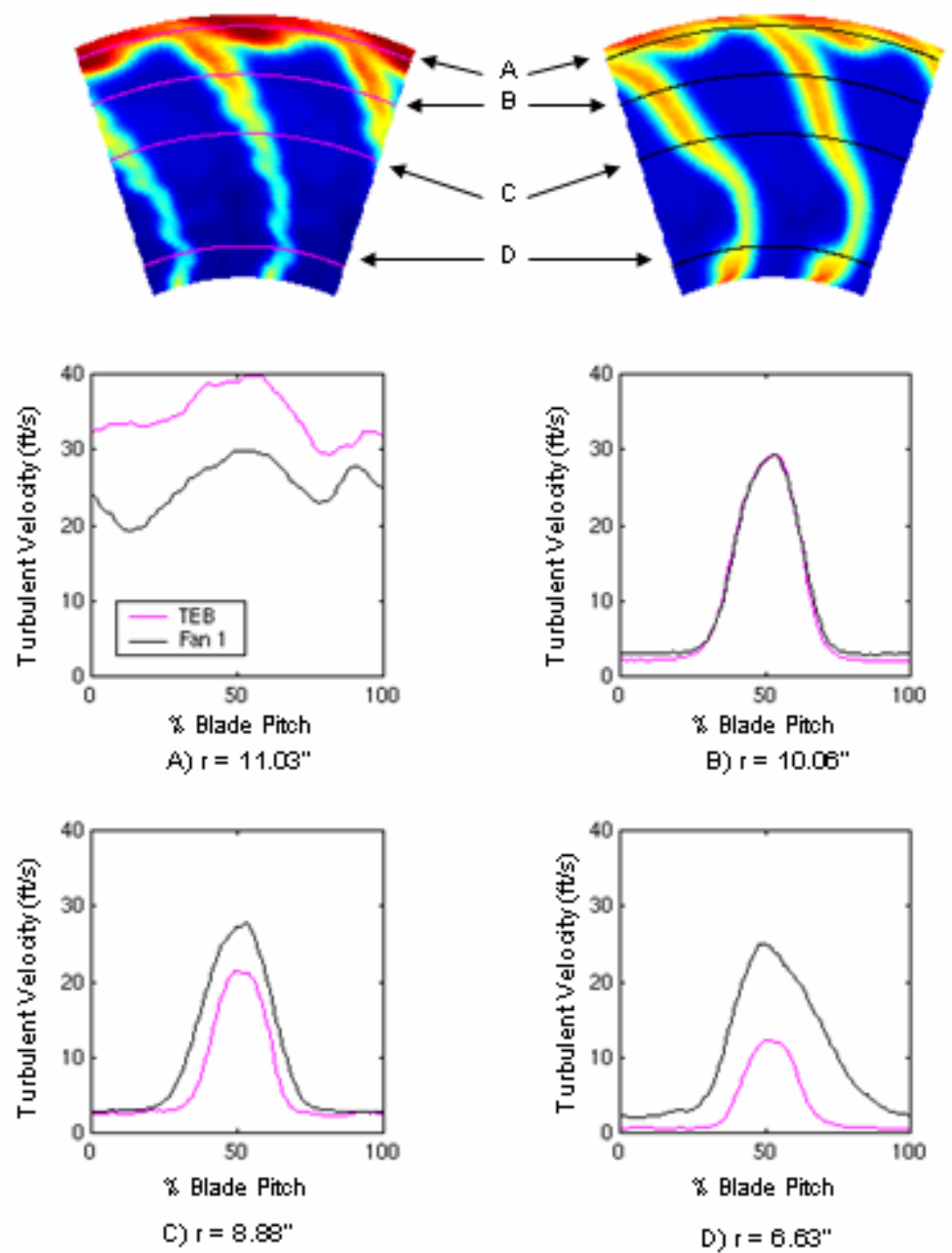

Figure 24.-Comparison of turbulent velocity profiles measured downstream of Fan1 (black) and Fan9 with 2\% TEB (magenta). 
Public reporting burden for this collection of information is estimated to average 1 hour per response, including the time for reviewing instructions, searching existing data sources, gathering and maintaining the data needed, and completing and reviewing the collection of information. Send comments regarding this burden estimate or any other aspect of this Davis Highway, Suite 1204, Arlingtongestions for reducing this burden, to Washington Headquarters Services, Directorate for Information Operations and Reports, 1215 Je $2202-4302$, and to the Office of Management and Budget, Paperwork Reduction Project (0704-0188), Washington, DC 20503.

\begin{tabular}{|l|l|l}
\hline 1. AGENCY USE ONLY (Leave blank) & $\begin{array}{c}\text { 2. REPORT DATE } \\
\text { March } 2007\end{array}$ & $\begin{array}{r}\text { 3. REPORT TYPE AND DATES COVERED } \\
\text { Technical Memorandum }\end{array}$
\end{tabular}

4. TITLE AND SUBTITLE 5. FUNDING NUMBERS

Noise Benefits of Rotor Trailing Edge Blowing for a Model Turbofan

6. $\operatorname{AUTHOR(S)}$

WBS 561581.02.08.03.03.01

Richard P. Woodward, E. Brian Fite, and Gary G. Podboy

7. PERFORMING ORGANIZATION NAME(S) AND ADDRESS(ES)

National Aeronautics and Space Administration

John H. Glenn Research Center at Lewis Field

Cleveland, Ohio 44135-3191

8. PERFORMING ORGANIZATION REPORT NUMBER

E-15802

9. SPONSORING/MONITORING AGENCY NAME(S) AND ADDRESS(ES)

10. SPONSORING/MONITORING AGENCY REPORT NUMBER

National Aeronautics and Space Administration

Washington, DC 20546-0001

NASA TM-2007-214666

AIAA-2007-1241

11. SUPPLEMENTARY NOTES

Prepared for the 45th Aerospace Sciences Meeting and Exhibit sponsored by the American Institute of Aeronautics and Astronautics, Reno, Nevada, January 8-11, 2007. Responsible person, Richard P. Woodward, organization code RTA, 216-433-3923.

12a. DISTRIBUTION/AVAILABILITY STATEMENT 12b. DISTRIBUTION CODE

Unclassified - Unlimited

Subject Category: 07

Available electronically at http://gltrs.grc.nasa.gov

This publication is available from the NASA Center for AeroSpace Information, 301-621-0390.

13. ABSTRACT (Maximum 200 words)

An advanced model turbofan was tested in the NASA Glenn 9- by 15-Foot Low Speed Wind Tunnel (9x15 LSWT) to explore far field acoustic effects associated with rotor Trailing-Edge-Blowing (TEB) for a modern, 1.294 stage pressure ratio turbofan model. The TEB rotor (Fan9) was designed to be aerodynamically similar to the previously tested Fan1, and used the same stator and nacelle hardware. Fan9 was designed with trailing edge blowing slots using an external air supply directed through the rotor hub. The TEB flow was heated to approximate the average fan exit temperature at each fan test speed. Rotor root blockage inserts were used to block TEB to all but the outer 40 and $20 \%$ span in addition to full-span blowing. A configuration with full-span TEB on alternate rotor blades was also tested. Far field acoustic data were taken at takeoff/approach conditions at 0.10 tunnel Mach. Far-field acoustic results showed that full-span blowing near $2.0 \%$ of the total flow could reduce the overall sound power level by about $2 \mathrm{~dB}$. This noise reduction was observed in both the rotor-stator interaction tones and for the spectral broadband noise levels. Blowing only the outer span region was not very effective for lowering noise, and actually increased the far field noise level in some instances. Full-span blowing of alternate blades at $1.0 \%$ of the overall flow rate (equivalent to full-span blowing of all blades at $2.0 \%$ flow) showed a more modest noise decrease relative to full-span blowing of all blades. Detailed hot film measurements of the TEB rotor wake at $2.0 \%$ flow showed that TEB was not every effective for filling in the wake defect at approach fan speed toward the tip region, but did result in overfilling the wake toward the hub. Downstream turbulence measurements supported this finding, and support the observed reduction in spectral broadband noise.

\begin{tabular}{|l|l|}
\hline 14. SUBJECT TERMS & 15. NUMBER OF PAGES
\end{tabular}

Aircraft engine performance; Engine noise; Noise reduction 30

\begin{tabular}{|c|c|c|}
\hline $\begin{array}{c}\text { 17. SECURITY CLASSIFICATION } \\
\text { OF REPORT } \\
\text { Unclassified }\end{array}$ & $\begin{array}{c}\text { 18. SECURITY CLASSIFICATION } \\
\text { OF THIS PAGE } \\
\text { Unclassified }\end{array}$ & $\begin{array}{c}\text { 19. SECURITY CLASSIFICATION } \\
\text { OF ABSTRACT } \\
\text { Unclassified }\end{array}$ \\
\hline
\end{tabular}



